\title{
FORMACIÓN DEL CONCEPCIÓN METROPOLITANO A TRAVÉS DE LOS GRANDES CONJUNTOS RESIDENCIALES. APORTACIONES DEL URBANISMO MODERNO ${ }^{1}$
}

\author{
THE FORMATION OF METROPOLITAN CONCEPCIÓN \\ THROUGH ITS LARGE RESIDENTIAL COMPLEXES. \\ CONTRIBUTIONS OF MODERN URBANISM
}

\section{PABLO FUENTES ${ }^{2}$ Y LEONEL PÉREZ 3}

\section{RESUMEN}

La consolidación de la zona como área industrial de importancia estratégica nacional tuvo entre sus principales consecuencias espaciales el emplazamiento de una cantidad importante de conjuntos habitacionales desarrollados partir de la instalación de diversos enclaves industriales, y consecuentemente, la conformación del territorio que actualmente se reconoce como Área Metropolitana de Concepción. Las ciudades que la conformaron pasaron a ser una zona privilegiada para establecer a obreros y empleados del sector industrial. Este trabajo detalla cómo este proceso de ordenación metropolitana se expresó a partir de la configuración de cuatro ejes urbanos que confluyen sobre la ciudad de Concepción y la transformación de ésta, a partir de un quinto eje, en el centro del sistema. Estos ejes de transporte hilvanaron una cantidad importante de conjuntos residenciales durante el siglo XX. Los principales resultados muestran que estas agrupaciones propusieron una nueva lectura del espacio público cuyo principal resultado fue la desaparición de la calle como corredor tradicional y la aparición de espacios verdes como articuladores de los conjuntos. Este ordenamiento habitacional, fundamentado en los principios de la arquitectura y el urbanismo moderno, llegaría a ser característico del Ârea Metropolitana de Concepción hasta los años setenta.

Palabras clave: Conjuntos residenciales, arquitectura moderna, urbanismo institucional.

${ }^{1}$ Resultados del proyecto Fondecyt No 11100239: “Grandes Conjuntos Habitacionales en la Región del Bío-Bío. La construcción institucional de la ciudad moderna, 1939-1973” y del proyecto Fondecyt No 1080566: “Transformaciones del Concepción Metropolitano. Estudio de las formas de crecimiento urbano a través de los grandes conjuntos residenciales (1992-2006)”.

${ }_{2}^{2}$ Doctor Arquitecto, Master en Conservación y Restauración del Patrimonio. Escuela de Arquitectura, Universidad del Bío-Bío. E-mail: pfuentes@ubiobio.cl

${ }^{3}$ Doctor Arquitecto. Facultad de Arquitectura y Centro EULA, Universidad de Concepción. E-mail: leperez@udec.cl 


\begin{abstract}
The consolidation of the zone as an industrial area of strategic national importance had as one of its principle spatial consequences the construction of an important number of residential complexes developed in response to the installation of diverse industrial enclaves and, consequently, led to the configuration of the territory that is now known as the Metropolitan Area of Concepción. The cities involved in this process became privileged zones for the establishment of workers and employees of the industrial sector. This study shows how the process of metropolitan organization was expressed in the configuration of 4 urban axes that converge on the city of Concepción and the transformation of the city into a fifth axis at the center of the system. These axes of transportation linked an important number of residential complexes during the $20^{\text {th }}$ century. The principle results show that these groupings proposed a new reading of public space in which the main outcome was the disappearance of the traditional street corridor and the appearance of new green spaces as the articulators of the complexes. This housing organization, based on the principles of modern architecture and urban planning, would come to be characteristic of the Metropolitan Area of Concepción in the 1970's.
\end{abstract}

Keywords: Residential complexes, modern architecture, institutional urbanism.

Recibido: 11.06.11. Aceptado: 07.02.12.

\title{
1. ANTECEDENTES DEL PROBLEMA HABITACIONAL EN EL ÁREA METROPOLITANA DE CONCEPCIÓN. POLÍTICAS Y PROYECTOS
}

$\mathrm{E}$

N 1906, EL TERREMOTO de Valparaíso originó en Chile la primera normativa institucional sobre vivienda económica. Sin embargo, este reglamento casi no tuvo repercusiones en el Área Metropolitana de Concepción. Durante las primeras décadas del siglo XX las intervenciones habitacionales destinadas al proletariado urbano habían sido prácticamente inexistentes, a no ser que se consideren las construcciones levantadas al alero de la industria carbonífera de Lota y Coronel y de la industria textil de Tomé que ocupaban sectores colindantes a estas ciudades, transformando la imagen urbana tradicional. Por lo general se trataba de conjuntos aledaños a las industrias, cuestión que permitía una conexión fluida entre lugar de trabajo y habitación. Se trataba de acciones -en un marco a veces altruista o meramente de conveniencia empresarial- que generaron barrios obreros con una arquitectura precaria aunque incipientemente funcionalista por la ajustada distribución de sus espacios arquitectónicos. En ellos los espacios públicos estaban supeditados a la ubicación de programas de necesidad colectiva. Estas iniciativas depositaban en la acción empresarial y privada la solución habitacional para sus empleados. Aquí radica el inicio 
del auspicio industrial en las intervenciones habitacionales en la región que teñirán una parte importante de las acciones de la segunda mitad del siglo XX y la aparición de nuevas formas de ocupación predial propias de los barrios obreros dependientes de la industria.

La actividad industrial de la zona aceleró su desarrollo en concomitancia con las alternativas económicas del momento derivadas de la recuperación financiera posterior a la crisis bursátil de 1929 (Navarrete e Hinostroza, 2009). Durante la década de los treinta, después del período de recesión económica, nuevos sistemas productivos fortalecieron el desarrollo económico en torno a la instalación de centros industriales y manufactureros, siendo las localidades de Chiguayante, Talcahuano, Penco, Lirquén, Tomé, Lota y Coronel los lugares elegidos. Aquí radica el origen del sistema vial tentacular en el Área Metropolitana de Concepción, ratificado por conjuntos habitacionales (Fig. 1) ${ }^{4}$. La solución del problema habitacional era parte de las demandas sindicales de principios del siglo XX que recogían los intereses proletarios internacionales y nacionales. Hacia finales de la década de 1930 los conventillos, agrupaciones habitacionales precarias al interior de las manzanas, ocupaban buena parte de la estructura urbana de Concepción, allí habitaban unas 40.000 personas (Pacheco, 1997: 38). En todos ellos había un denominador común: la mala calidad habitacional (Campos Harriet, 1979: 180).

Para entonces, el Estado fue comprometiendo su quehacer institucional paulatinamente con el problema habitacional. A este objetivo corresponde la creación de la Caja de Habitación Popular en 1936 por la Ley 5.950 que concretó un número significativo, aunque no suficiente, de unidades habitacionales, pero que tuvo repercusión en todo el territorio. Esta institución transmitió los intereses renovadores de la arquitectura moderna, especialmente aquéllos derivados de las nociones higienistas de principios del siglo XX cuya traducción en el diseño será determinado por la racionalización y el funcionalismo habitacional, así como la incorporación de diversas infraestructuras indispensables, como agua potable, alcantarillado, alumbrado público, electricidad y gas. Sus proyectos, en el pericentro y en la periferia de la ciudad, elevaron la densidad demográfica e incorporaron el lenguaje arquitectónico moderno y un nuevo significado sobre los es-

\footnotetext{
${ }_{4}^{4}$ Algunas de las manufactureras instaladas fueron la Industria textil Grace y Cía. (Chiguayante, 1920), fábrica de Loza (Penco, 1930), fábrica de Paños FIAP (Tomé, 1932), Vidrios Planos (Lirquén, 1936). Ver http://raravenahistoria2008.blogspot.com/2008/11/historia-industria-textil -chiguayante.html
} 


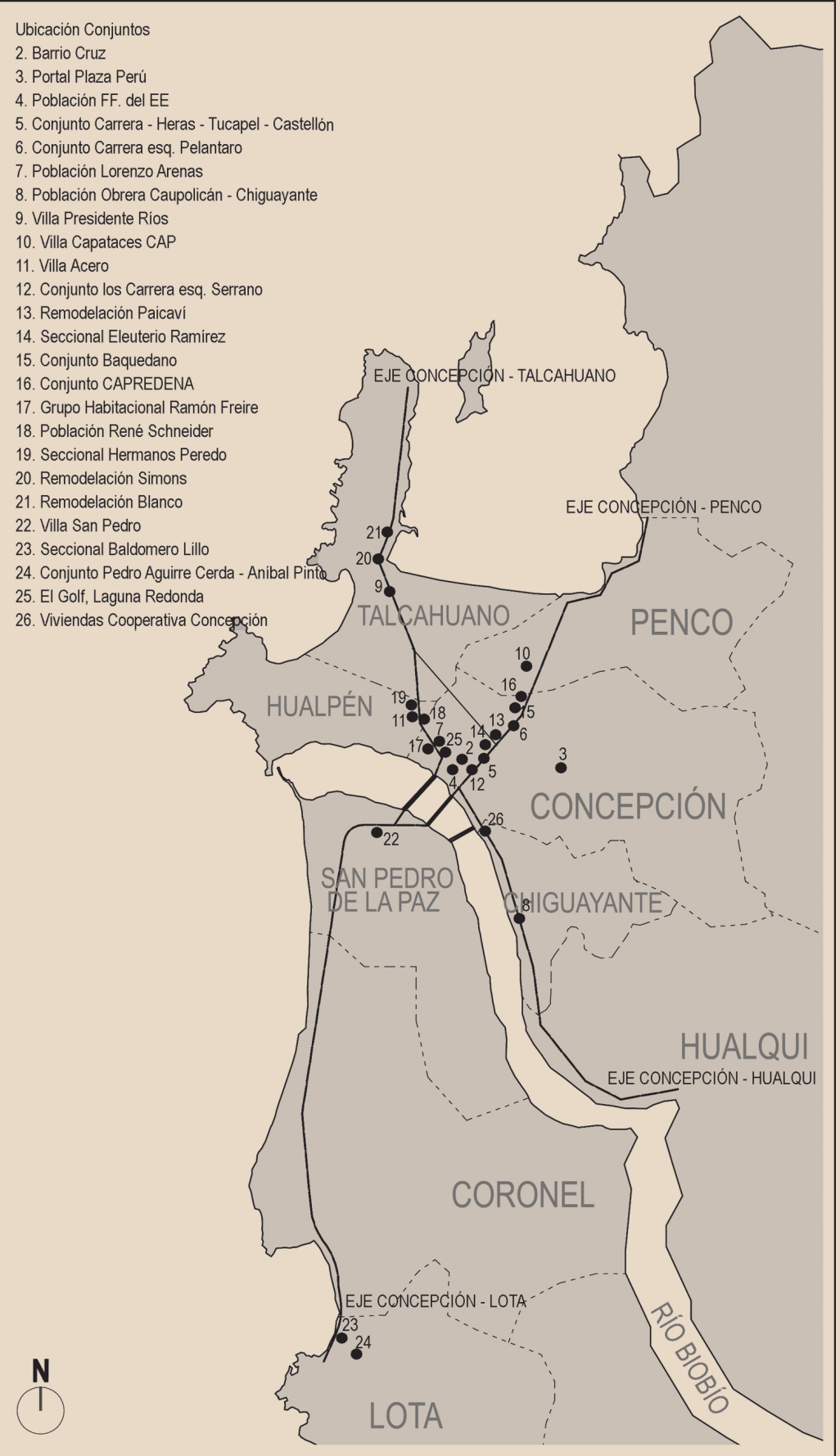

Figura 1. Ubicación de conjuntos habitacionales sobre ejes viales. (Dibujo Francisca Valencia). 
pacios públicos, denotando una ocupación comunitaria, característica de las transformaciones del segundo tercio del siglo XX. Dicho de otro modo, de la parcelación individual y privada se pasó a una subdivisión grupal y pública.

A finales de la década de 1940 la ubicación de la población menesterosa en la ciudad de Concepción había cambiado. La aparición en los extrarradios urbanos de numerosas poblaciones callampas sin infraestructuras acrecentaba el problema. En este cambio del conventillo a la población callampa influyó notoriamente el proceso de industrialización de la zona. La razón estaba en la emigración a la región de un nutrido contingente de obreros y la carencia de viviendas producida después del devastador terremoto de 1939 que expulsó del centro de la ciudad a los más necesitados (Pacheco, 1997: 39).

Entre las primeras intervenciones residenciales del siglo XX auspiciadas por instituciones estatales se reconocen pequeños conjuntos con alguna incidencia en la escala de la ciudad y al interior de su estructura. La división en tres partes de la manzana poniente de la Plaza Cruz en Concepción, ejecutada para empleados de ferrocarriles en 1927, aparece como una intervención ajustada al trazado de damero de la ciudad tradicional (Fig. 2). Su emplazamiento, adyacente a la plaza mencionada, constituye uno de los barrios característicos y tradicionales de la ciudad (Schultz, 1983)5. Se trata de un conjunto de viviendas pareadas de un nivel que combinan variados tipos arquitectónicos eclécticos propios del período.

Posteriormente, las catastróficas consecuencias del terremoto de 1939 catalizaron la construcción de los primeros conjuntos de impacto urbano con auspicio estatal. Los pabellones de viviendas de emergencia construidos en madera después del terremoto 1939, ubicados en bordes disponibles de la ciudad, como el Parque Ecuador y la Avenida Manuel Rodríguez, son los primeros intentos por construir institucionalmente la vivienda popular, alterando la estructura urbana tradicional de la ciudad ${ }^{6}$.

A partir de entonces el Estado comenzó a ejercer una labor comprometida con un hondo proceso de modernización nacional que se puede fechar a fines de los años treinta, con el afianzamiento en el poder político del Frente Popular liderado por el Presidente radical Pedro Aguirre Cerda.

\footnotetext{
${ }^{5}$ También ver de M. A. B. “Concepción y sus barrios”, El Sur, domingo 17 de julio de 1983-III.

${ }^{6}$ Varios conjuntos de este tipo se levantaron también en Quirihue, San Carlos, Los Ángeles y otras ciudades como parte de las iniciativas de reconstrucción posterremoto de 1939.
} 


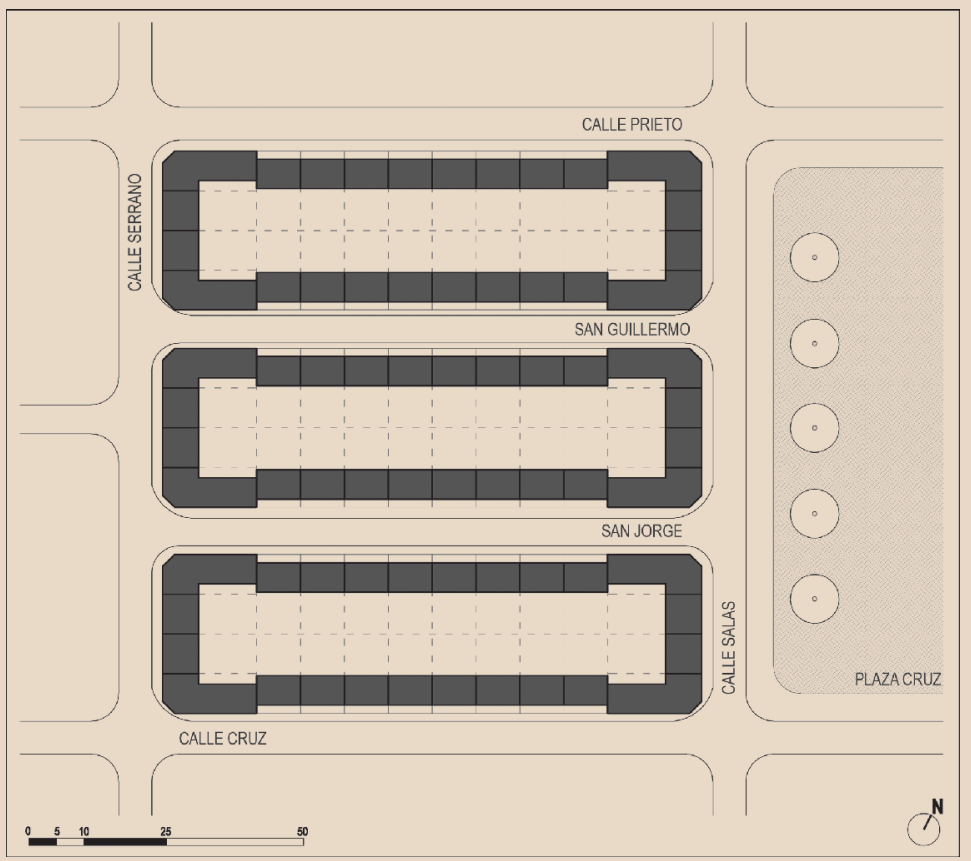

Figura 2. Barrio Cruz. (Dibujo Francisca Valencia).

En esta ocasión, la autoridad hizo urgente la discusión del problema de la vivienda a través de acciones concretas, cuestión particularmente tratada en el Congreso de la Vivienda en 1939 desarrollado en Buenos Aires, donde representantes de la Caja de la Habitación Popular defendían el papel protector del Estado respecto de la falta de vivienda. En 1940 Santiago fue escenario de la primera Exposición de la Vivienda auspiciada por el gobierno, evento que denunciaba las urgentes carencias residenciales de un alto porcentaje de población chilena que además contó con la promoción de una vivienda social tipo instalada en un novedoso pabellón en la Alameda Bdo. O'Higgins diseñado por los jóvenes arquitectos Enrique Gebhard, Waldo Parraguez y Jorge Aguirre, generación que atendía los problemas nacionales desde una perspectiva racionalista. En 1945 se desarrolló en la capital la Semana de la Vivienda, reunión que congregó arquitectos y personal del gobierno para discutir el alto déficit habitacional nacional, cuyas estimaciones coincidían en torno a las 300.000 unidades$^{7}$.

${ }^{7} \mathrm{La}$ "Semana de la Vivienda" fue un congreso que se realizó entre el 4 al 11 de agosto de 1945. Fue auspiciado por el Colegio de Arquitectos y presidido por Alberto Risopatrón. Al evento 
En paralelo el Estado emprendió con una actitud renovadora la planificación de nuevos conjuntos al alcance de las clases regionales emergentes. Se trataba de extender a las provincias la modernización nacional en congruencia con los principios de la arquitectura racionalista.

El Área Metropolitana de Concepción pasaría a ser una zona privilegiada en el emplazamiento de una cantidad importante de conjuntos habitacionales. La razón residía en la consolidación de la zona como área industrial de importancia estratégica nacional: las industrias fueron emplazadas próximas a las principales vías de tráfico urbano e interurbano, líneas de ferrocarriles y a los puertos marítimos más importantes que correspondían a la organización de las redes productivas establecidas a partir del terremoto de 1939. Para el caso, las principales ciudades impulsaron el desarrollo manufacturero y con ello la necesidad de establecer a obreros y empleados. La ciudad de Concepción se transformaría en el centro del sistema admitiendo, a través de su papel articulador, actividades políticas, administrativas, educacionales, comerciales y de servicios. Por su tamaño y jerarquía urbana, se promovió en ella la instalación de numerosos conjuntos residenciales establecidos bajo principios del urbanismo moderno.

\section{APORTACIONES DE LA INDUSTRIA Y EL ESTADO EN EL SURGIMIENTO DE LOS PRIMEROS CONJUNTOS RESIDENCIALES}

Uno de los primeros emprendimientos estatales, y acaso uno de los más particulares, es el conjunto habitacional de Plaza Perú (Fig. 3) que, originado por el terremoto de 1939, reniega de las ideas del urbanismo moderno e insiste en ideales formales más conservadores. Ubicado en el extremo sur de la Diagonal Pedro Aguirre Cerda de Concepción, fue un concurso convocado en 1941 por la Corporación de Reconstrucción y Auxilio y obtenido por los arquitectos Aránguiz, Ovalle y Ugarte, que alteraba significativamente la traza urbana ortogonal de la ciudad. Aquí por encargo de la Caja de la Habitación Popular, se ubicó un conjunto semicircular en torno a una plaza que articulaba la ciudad y la Universidad de Concepción. La Compañía de Acero del Pacífico, CAP, recién formada, adquirió tres de los bloques en construcción para albergar a los profesionales extranjeros que

fueron invitados un conjunto de especialistas, técnicos y políticos. Ver Risopatrón, A., "Nuestra Institución Gremial. La Asociación y el Colegio de Arquitectos de Chile". Arquitectura y Construcción, No 11, 1947, p. 39. Ver también Cáceres, 1992: 104. 


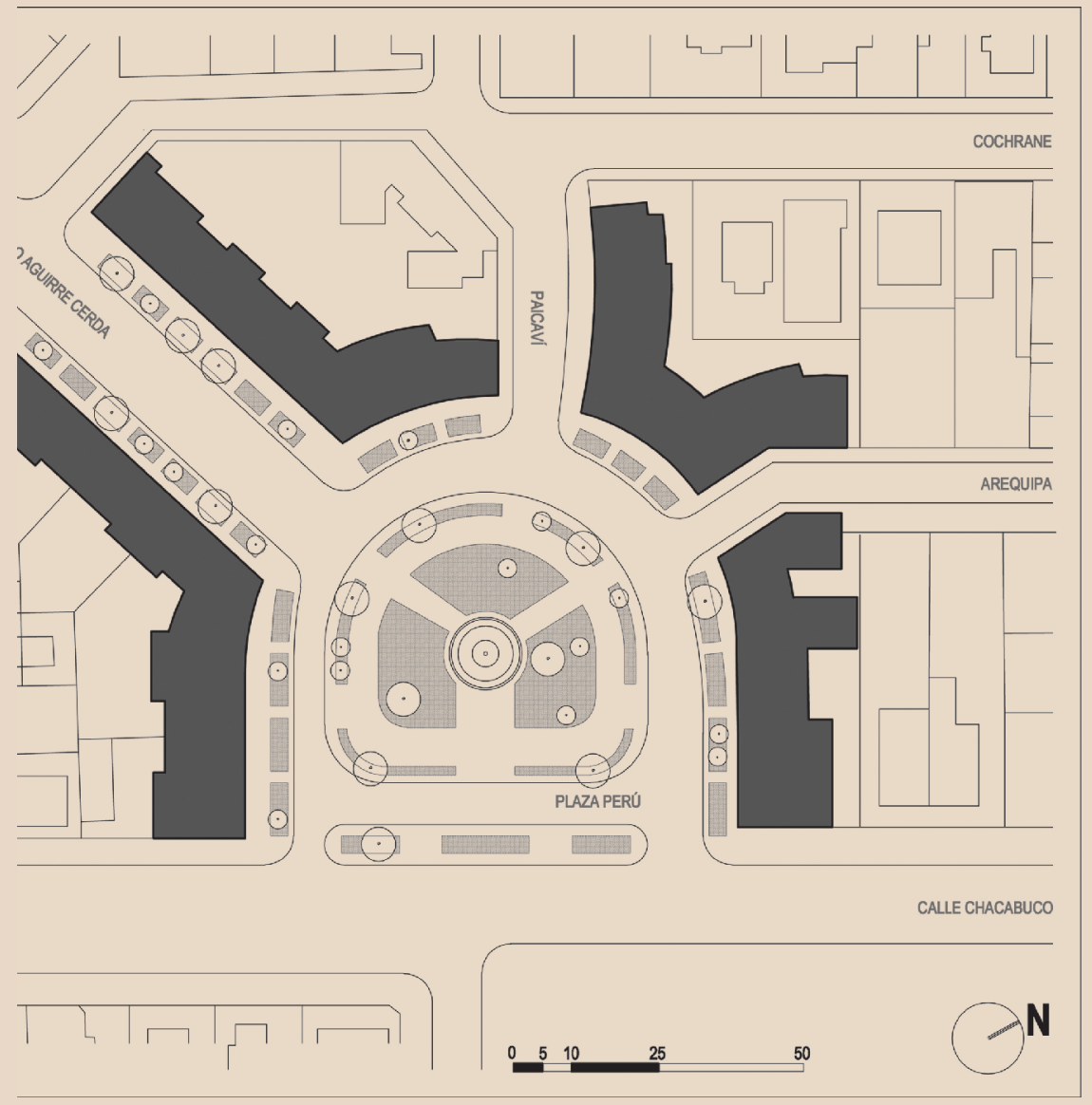

Figura 3. Edelberto Navarrete et al. Portal Plaza Perú (1942-45). (Dibujo Francisca Valencia).

venían a instalar la siderúrgica. El proyecto, terminado en 1949, pretendía consolidar un sector central de renovación urbana posterior a la catástrofe. Su diseño, más preocupado por la configuración del espacio público con aspiraciones esteticistas que por incorporar anhelos del urbanismo moderno, afianzó un lugar con carácter propio de la ciudad.

En paralelo se comenzaron a desarrollar proyectos que paulatinamente incorporaban los argumentos del urbanismo contemporáneo. Una de las primeras intervenciones modernas inscritas en la trama de Concepción corresponde a la población de FF. del EE., empresa estatal que dedicó importantes recursos a la construcción de habitaciones para sus empleados. El conjunto fue diseñado por Enrique Gebhard en 1942 y se ubica en la 
manzana delimitada por las calles Prat, Prieto, Serrano y Cruz, tangencial al eje Concepción-Talcahuano (Fig. 4). Es una composición que reconoce al corredor Prat con una fila de viviendas continuas de dos niveles que limita el conjunto. Hacia el interior se dispone un pasaje en "T" cuyo pasaje central, conectado a Serrano, separa dos sectores habitacionales ocupados por cuerpos alternados aislados de dos niveles en cuyos intersticios se desarrollan antejardines y patios interiores. Aquí se detecta por primera vez la alteración de la trama urbana y su fachada continua, a través de entrantes y salientes. Se estimula así el interior de la manzana y la discontinuidad de sus bordes fundando una unidad habitacional alternativa a la ciudad tradicional, mezclando espacios verdes, públicos y semipúblicos.

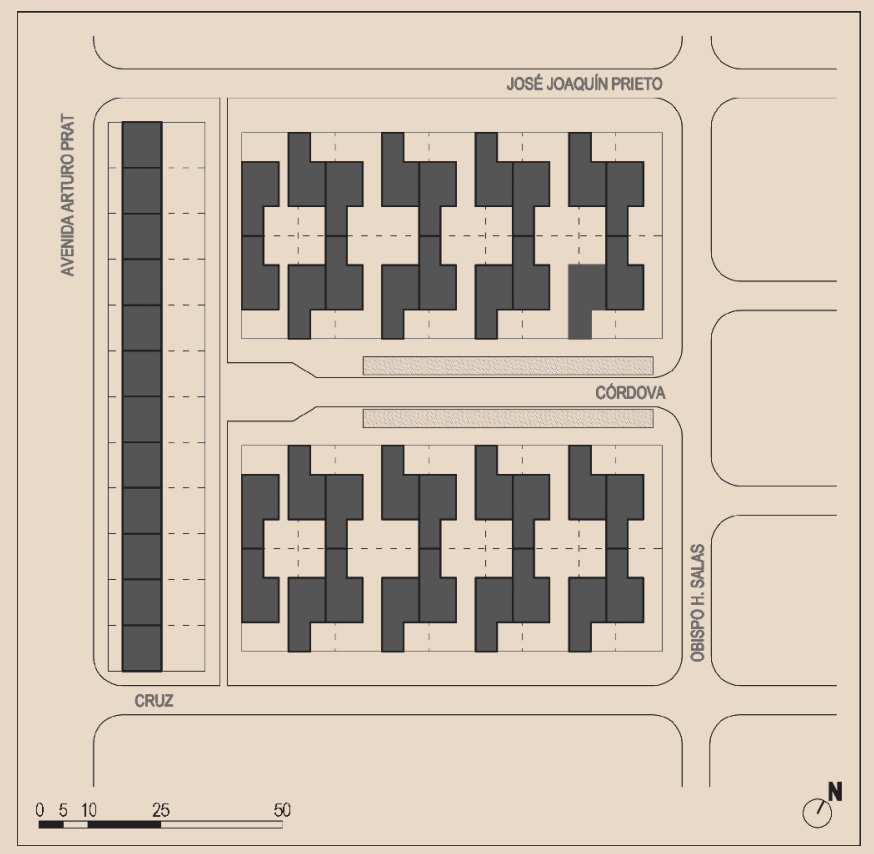

Figura 4. Enrique Gebhard. Población FF. del EE. (1942). (Dibujo Francisca Valencia).

También a comienzos de los años 40 la Caja de la Habitación Popular construyó uno de sus primeros conjuntos en Concepción. Para el caso la calle Los Carrera comenzó su transformación en avenida, motivo por el que varios conjuntos habitacionales se emplazaron en este eje, colaborando 
con la jerarquía espacial requerida aunque sin éxito en la configuración armónica de esta vía. Este tipo de agrupaciones ratifica la estructura de damero después del terremoto de 1939. Aunque racionaliza los terrenos es una transformación moderada respecto a las premisas del urbanismo moderno. Un caso es la Población Bío-Bío, de la Caja de la Habitación, que ocupa $3 / 4$ de la manzana comprendida entre las calles Los Carrera, Tucapel, Heras y Castellón (1945) (Fig. 5). Este agrupamiento ocupa la manzana en dos partes divididas por un pasaje oriente-poniente. Aparecen bloques de tres niveles en los costados oriente, poniente y sur, sus fachadas interiores muestran balcones corredores que dan vida al interior y sirven de accesos a las viviendas; el resto son casas continuas de una planta.

Siguiendo este tipo de intervención en las manzanas tradicionales y en la transformación de la avenida Los Carrera, el conjunto en la esquina con Pelantaro (Fig. 6) avanza sobre la apropiación de la urbanística moderna al disponer 6 bloques aislados y simétricos sobre un poco más de 1/4 de manzana. Son cuerpos paralelos de 4 niveles, orientados de norte a sur; dos de ellos más largos en los costados y en el centro dos menores albergan un patio central.

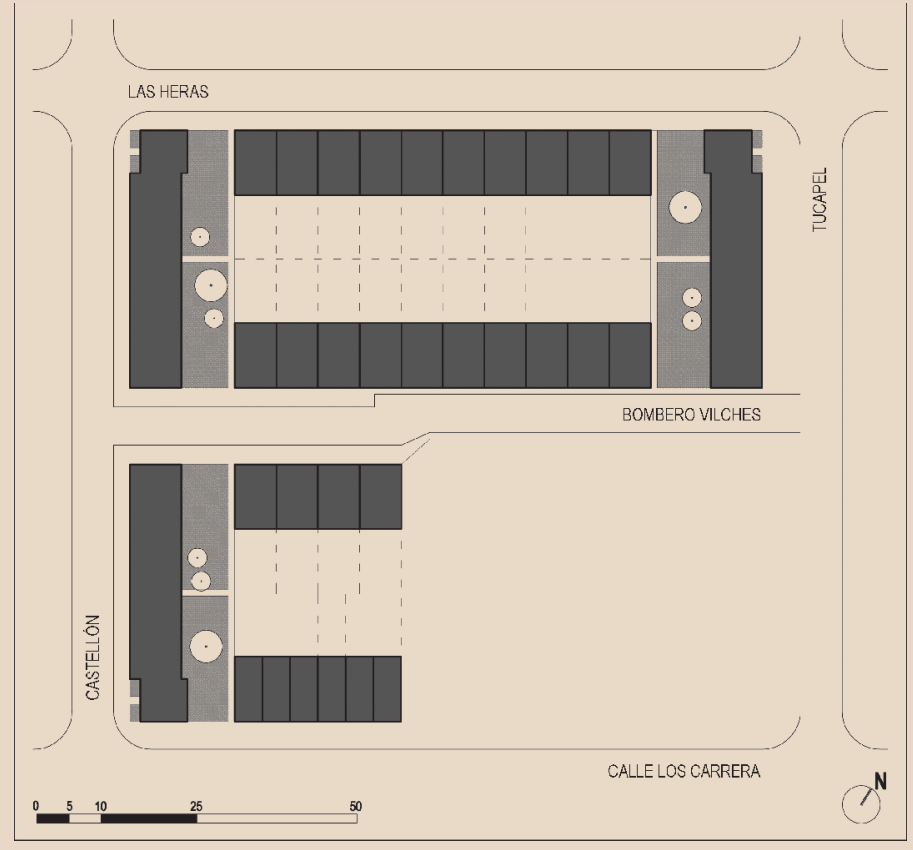

Figura 5. Caja de la Habitación Popular. Carrera, Tucapel, Heras y Castellón (1945). (Dibujo Francisca Valencia). 


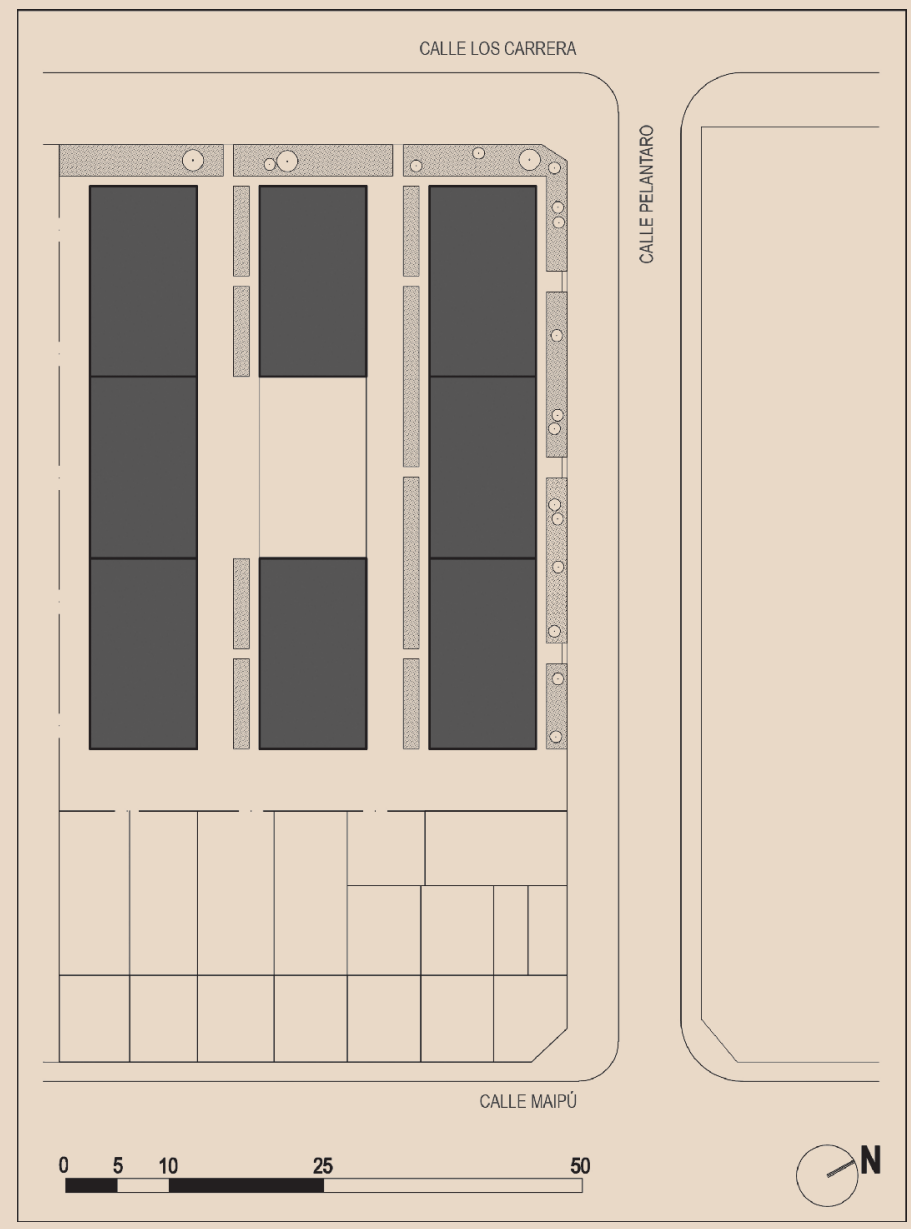

Figura 6. Conjunto Carrera esq. Pelantaro. (Dibujo Francisca Valencia).

Confirmando el criterio de consolidación de los ejes principales de la conurbación y evidenciando la introducción de la teoría del urbanismo moderno en la región, aparece la Población Lorenzo Arenas (1942) (Fig. 7) en Concepción. Está ubicada junto a la Avda. 21 de Mayo, entonces única vía de conexión a Talcahuano, y a la línea férrea. Está adyacente a la ciudad fundacional y tangente a la Laguna Redonda en la periferia norte de la ciudad. Es, probablemente, el primer conjunto que se emplaza en uno de los márgenes geográficos inaugurando los tipos urbanos alternativos a la estructura de damero tradicional. Su diseño fue ejecutado por la Caja de 


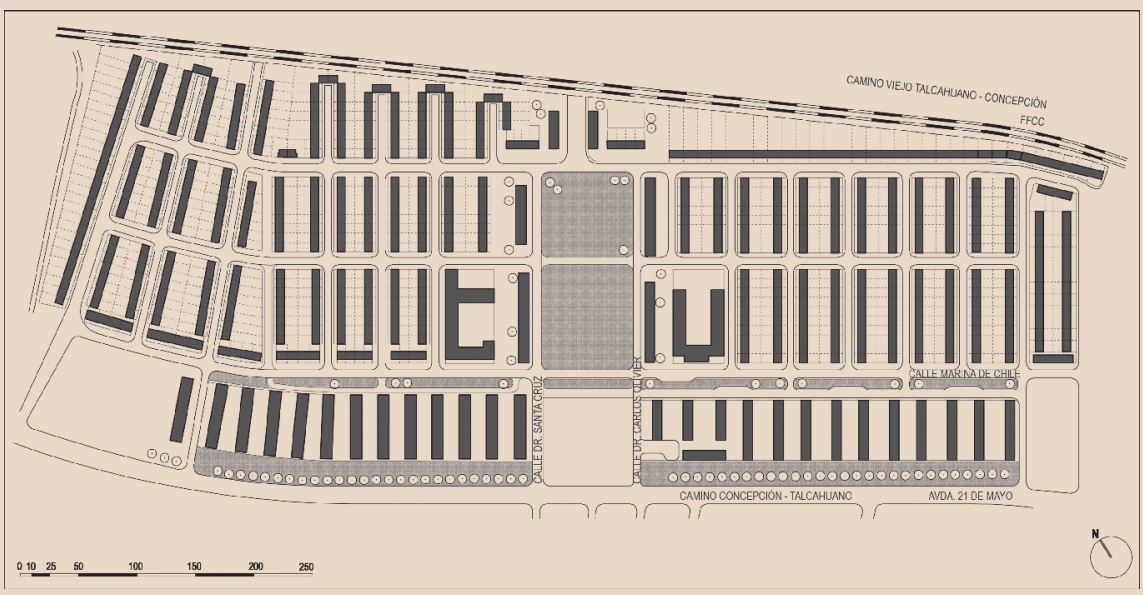

Figura 7. Caja de la Habitación Popular. Población Lorenzo Arenas (1942). (Dibujo Francisca Valencia).

la Habitación Popular para el Seguro Social. Su estructura vial considera vías externas perimetrales, fundamentalmente vehiculares, que limitan el conjunto; calles principales que lo conectan con el sector; secundarias y terciarias (pasajes) que sirven a las viviendas del sector (Vallejos, 2009). El conjunto está formado por bloques habitacionales de tres plantas y viviendas en un nivel. Se organiza en una franja de bloques paralelos de tres niveles, orientados de nororiente a surponiente flanqueados por la Avda. 21 de Mayo y la calle Marina de Chile; son cuerpos aislados, con escaleras y pasillos exteriores, rodeados de áreas verdes y separados de las circulaciones vehiculares. Hacia el oriente, y detrás de esta franja, se dispusieron viviendas en manzanas pequeñas separadas por calles y pasajes. En el centro, entre las calles Dr. Santa Cruz y Dr. Carlos Oliver, entre edificios en altura, se dispuso un área de abastecimientos y recreación que articulaba ambas tipologías y estimulaba la vida comunitaria. Esta forma de participación social supuso un adelanto sobre las unidades vecinales características de medio siglo.

Por el sur, la población obrera Caupolicán-Chiguayante (Fig. 8) también incorporaba las teorías modernas. El concurso (1946) dirigido por la Caja de Habitación Popular fue ganado por los arquitectos Oreste Depetris, Norman Day, R. Argandoña y A. González. Era una población para obreros de la fábrica textil homónima en el sector sur de Chiguayante. Su objetivo era "el de resolver un problema planteado por una firma industrial que deseaba cooperar a la labor de edificación de viviendas higiénicas y econó- 


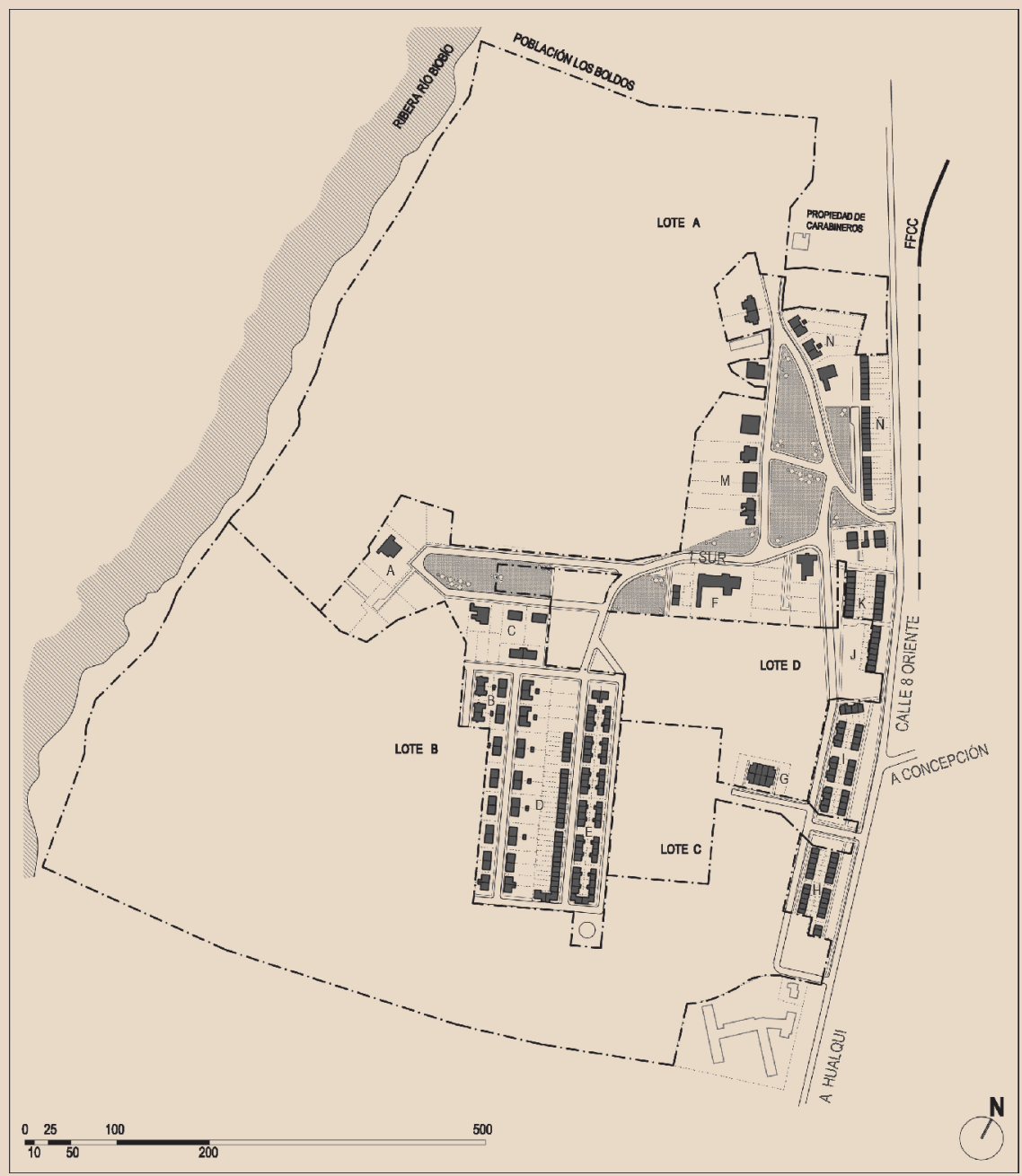

Figura 8. Oreste Depetris et al. Población Obrera Caupolicán-Chiguayante (1946). (Dibujo Francisca Valencia).

micas". Aquí se detecta el inicio de la opción institucional por auspiciar conjuntos habitacionales modernos con apoyo industrial en la zona, cuestión característica de la segunda mitad del siglo XX.

Su programa destacaba viviendas para obreros y trabajadores solteros,

8 "Concurso población obrera Caupolicán-Chiguayante". Arquitectura y Construcción, № 5, abril, 1946, p. 75. El Concurso de anteproyectos para la Población Obrera de la Fábricas Textiles 
la incorporación de una "casa social", gimnasio cubierto, sala de espectáculos y "almacenes cooperativa", cubriendo las necesidades de todos los grupos sociales'. Su diseño expresaba el deseo por el desaparecimiento de la "calle corredor" (Fuentes, 2006: 27). Así, la separación de las circulaciones peatonales y vehiculares y la individualización de los espacios públicos de los privados se comprometían con la nueva urbanística. El proyecto organizaba viviendas en bloques aislados y pareadas en pasajes de menor escala, todas abrazaban en el centro un estadio que vitalizaba el lugar. Este conjunto apenas materializó en 1951 algunas viviendas del proyecto original.

\section{RATIFICACIÓN DE LOS PRINCIPIOS MODERNOS EN LA 2a MITAD DEL SIGLO XX. PROMOCIÓN INDUSTRIAL EN LA VIVIENDA}

A fines de la década de los cuarenta, cuando el escenario internacional denotaba las vicisitudes bélicas de mediados de siglo XX, las repercusiones en el desarrollo de la arquitectura residencial chilena tuvo en la ideología del urbanismo funcionalista un eco decisivo.

La formación metropolitana de Concepción estuvo influida por el desarrollo industrial. La actividad financiera, administrativa y cultural quedó reunida en el centro urbano de Concepción. Asimismo, la actividad siderúrgica, petroquímica y portuaria en Talcahuano y San Vicente. Estas actividades se sumaron a los núcleos industriales en Penco, Lirquén y Tomé y fortalecieron los centros mineros de Lota y Coronel, conformando un extenso complejo urbano (Campos Harriet, 1979: 207) ${ }^{10}$.

La creación en 1947 de la siderúrgica CAP, en la Bahía de San Vicente, en Talcahuano, una estrategia estatal de desarrollo económico gestionada por la CORFO y con apoyo tecnológico estadounidense, permitió diseñar por primera vez en Chile una ciudad obrera basada en las estrategias programáticas modernas. Era una solución modelo nueva en su género. Este tema, en la base del debate latinoamericano sobre las unidades vecinales, respondía

de Chiguayante fue organizado por la Caja de la Habitación y se presentaron 19 arquitectos. El orden de los premiados fue: $1^{\circ}$, No 374 , Anteproyecto de Oreste Depetris y Norman Day; $2^{\circ}$, No 1573 de Osvaldo Buccicardi y Hernán Middleton; 3ㅜ, № 1388 de Ignacio Santa María y Antonio Escobar; el 4º, No 1481 de Jorge Costabal, René López, José Cruz y Adolfo Mujica; el 5º, No 481 de Alfredo Johnson, Carlos Feuereisen y Manuel Echeverría, el 6º de Santiago Roi. Ver Arquitectura y Construcción, No 4, marzo, 1946, p. 108.

9 "Concurso población obrera Caupolicán-Chiguayante", Arquitectura y Construcción, No 5, Santiago de Chile, abril, 1946, p. 79.

${ }^{10}$ Citado en Campos Harriet (1979), p. 207. 
al problema de la vivienda originada en la explosión demográfica y urbana que sufrían los países de la región hacia mediados del s. XX.

El proyecto, iniciado en 1949, fue encargado a Sergio Larraín G-M y Emilio Duhart, jóvenes arquitectos que desarrollaron una ciudad obrera apropiando variados aspectos de las teorías modernas (Fig. 9). El proyecto fue aprobado en 1951 por la Corporación de Reconstrucción y Auxilio.

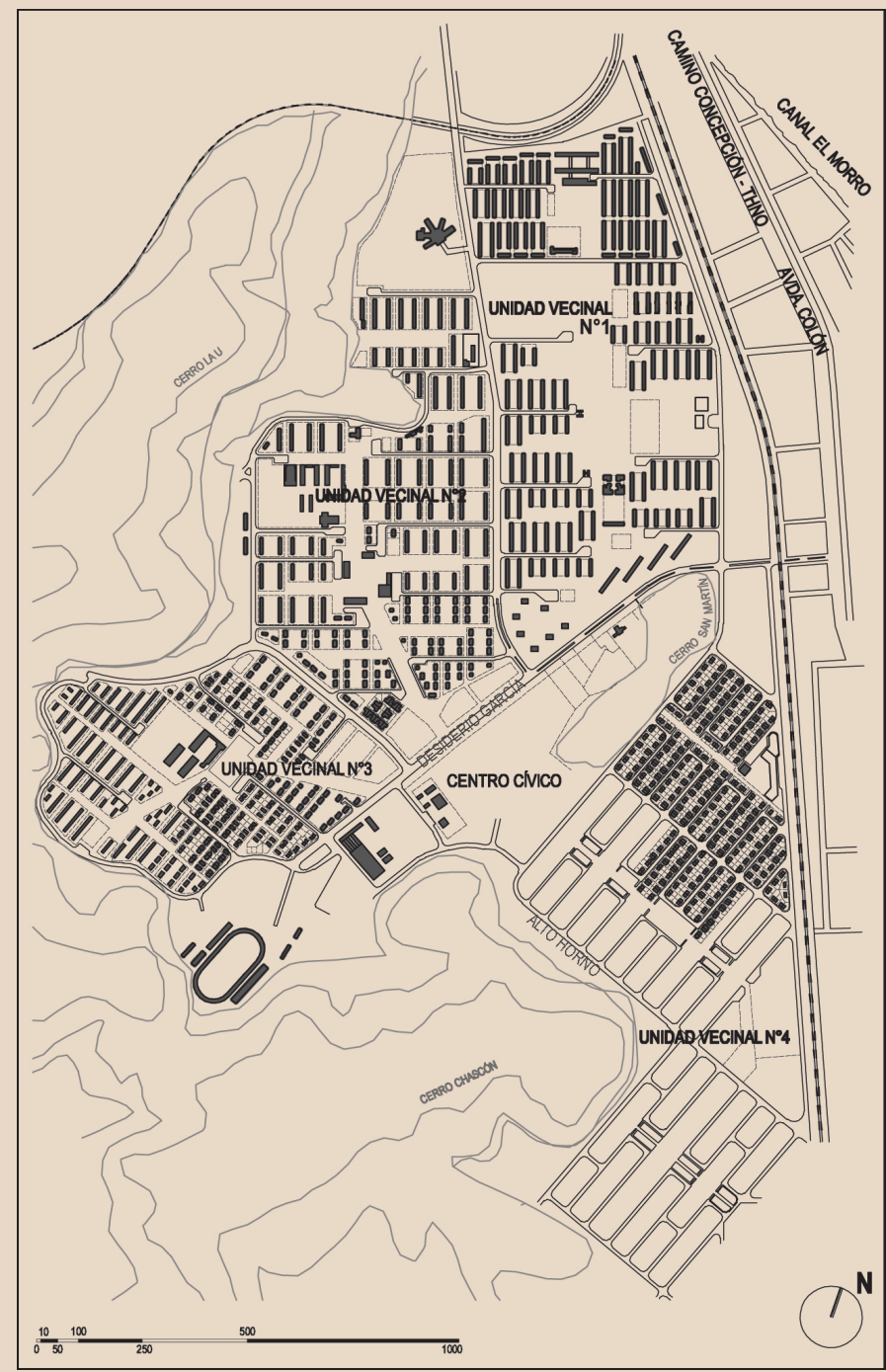

Figura 9. Sergio Larraín G-M., Emilio Duhart. Villa Presidente Ríos (1949). (Dibujo Francisca Valencia). 
El lugar escogido estaba rodeado por el cerro la "U", al oriente de la siderúrgica y equidistante de Concepción y Talcahuano. Poseía inmejorables condiciones de accesibilidad desde los principales asentamientos de la región y mantenía proximidad a puertos y líneas ferroviarias. Su organización territorial y de conectividad establecieron una concepción metropolitana determinando el destino urbano de varias comunas.

Consideró un trazado vial mayor que escindía el área en 5 partes en concomitancia con las ensenadas naturales del cerro mencionado; cuatro correspondían a unidades vecinales y en el centro a un núcleo cívico y de equipamientos que articulaba la totalidad. La Villa Presidente Ríos (1949), destinada para 30.000 habitantes, fue dividida en 4 unidades vecinales de 7.500 personas cada una; su tamaño y densidad respondían a las necesidades educacionales de las familias. El proyecto, cuyos alcances no fueron del todo ejecutados, cumplía con aquellas principales cuestiones proyectuales de la urbanística contemporánea, por ejemplo: separación de las funciones vehiculares de las peatonales, ubicación de los volúmenes rodeados de áreas verdes, división por macromanzanas y centros de abastecimiento en los núcleos, todas cuestiones que se oponían al tratamiento de bordes compactos de la ciudad tradicional (Fuentes y Pérez, 2007).

El emplazamiento de esta nueva ciudad ratificaba un tipo de crecimiento urbano lineal, pero discontinuo; es decir, eran asentamientos aislados dependientes de un eje vial jerárquico del área metropolitana donde la infraestructura viaria vinculaba conjuntos residenciales que estaban espacialmente separados.

A partir de esta intervención la CAP auspició una importante cantidad de grupos residenciales de forma directa, promoviendo la venta de viviendas sin intermediarios a sus empleados y obreros, o indirecta, en asociación con instituciones dedicadas a la acción habitacional como la Corporación de Reconstrucción y Auxilio y la Caja de la Habitación. La acción indirecta también consideró la gestión entre la industria, la Asociación de Ahorro y Préstamo y empresas particulares; y asimismo, acciones entre la industria y cooperativas de edificación. A partir de 1962, el reglamento de la CAP estableció préstamos en combinación con las Asociaciones de Ahorro y Préstamo y la CORVI (De la Fuente et al., 1983: 1-21).

En este marco de conciliaciones entre la industria, entidades estatales y particulares la CAP erigió varios conjuntos, entre los que destacan La Villa Los Cóndores, la Villa Capataces CAP, la Villa Acero, la Villa Collao y la Villa Llacolén en San Pedro. La mayoría admitió la descentralización urbana, mejoró los vínculos con áreas verdes y modificó los principios de los 
CIAM, sobre todo en cuanto a la reducción de las dimensiones del espacio público y al fomento de las relaciones comunitarias. Estos factores caracterizaron los emprendimientos desarrollados entre 1950 y 1970.

Por el contrario, otras poblaciones incorporaron argumentos urbanísticos que interpelaban a la vida comunitaria. La Villa Capataces CAP (1965) (Fig. 10) se ubicó adyacente a la ruta que une Concepción con Pen-

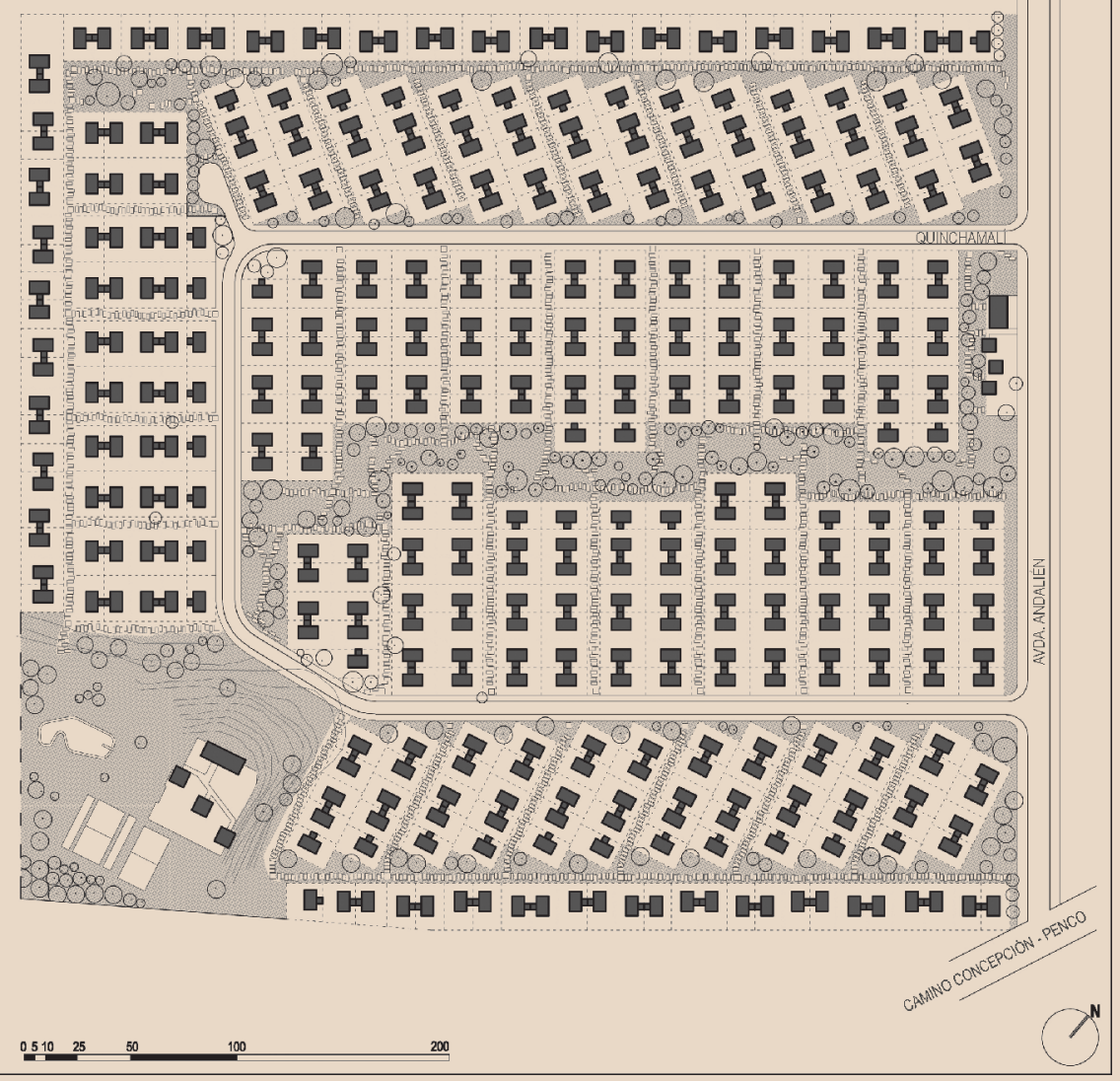

Figura 10. Santiago Roi y Ricardo Hempel. Villa Capataces CAP (1965-1968). (Dibujo Francisca Valencia). 
co. Sus arquitectos fueron Santiago Roi y Ricardo Hempel. El terreno, un rectángulo de $430 \times 470 \mathrm{~m}$, es adyacente a la Avda. Andalién. Su proyecto se organizó como una unidad vecinal. En su centro se estableció una manzana de 200 x 300 m, atravesada por un jardín peatonal interior y rodeada por una avenida principal en " $U$ " cuyos extremos sirven de acceso desde la avenida mencionada. La manzana fue rodeada por una franja también en " $U$ " de viviendas y equipamientos. Consideró varios tipos de viviendas de madera de un nivel, mayoritariamente pareadas, con antejardín y patio. La senda peatonal permitía conectar un pequeño centro comercial en el costado fronterizo con la vía principal con una escuela y zona recreativa en la esquina sur del terreno. A partir de la avenida principal se dispusieron pasajes de penetración hacia las viviendas de unos $80 \mathrm{~m}$, perpendiculares hacia el centro y diagonales hacia la periferia, evitando de este modo la continuidad espacial, y por tanto, admitiendo la formación de pequeñas vecindades. Este loteo es crítico con el urbanismo funcionalista ya que privilegia la vida urbana restando calles de acceso y promoviendo pequeños pasajes y sendas verdes, superando los ideales macroespaciales y macroviales del urbanismo moderno. Era una posición más próxima a la teoría sobre el "sentido de vecindad" de Thomas Sharp (Sharp, 1947: 103). Esta parcelación relativiza el concepto de espacio colectivo, de mayores dimensiones, por uno comunitario, más aprehensible, alterando notoriamente la percepción del espacio público.

Por su parte, la Villa Acero (1965) (Fig. 11) corresponde a una gestión habitacional emprendida entre trabajadores de la CAP, organizados en cooperativas y la sección de bienestar de la empresa. El proyecto fue encargado igualmente a los arquitectos Roi y Hempel. Se emplazó en un terreno de 15 ha, al poniente de la Avda. Colón, camino a Talcahuano. Similar al caso anterior, se organizó una manzana en el centro del conjunto, de forma ovoidal, que también cruza una senda peatonal. Una calle principal que nace y termina en el mismo lugar en Colón, rodea esta manzana. En particular, una calle en cul de sac se desprende de esta avenida para alcanzar el sector surponiente del terreno. Las viviendas de madera, pareadas y aisladas, se organizan en pasajes cortos perpendiculares a la vía principal sin continuidad espacial. En Colón se ubicaba el equipamiento público junto al acceso principal, en el otro extremo de la senda peatonal interior se ubicaba la escuela en equidistancia relativa a las viviendas del conjunto. 


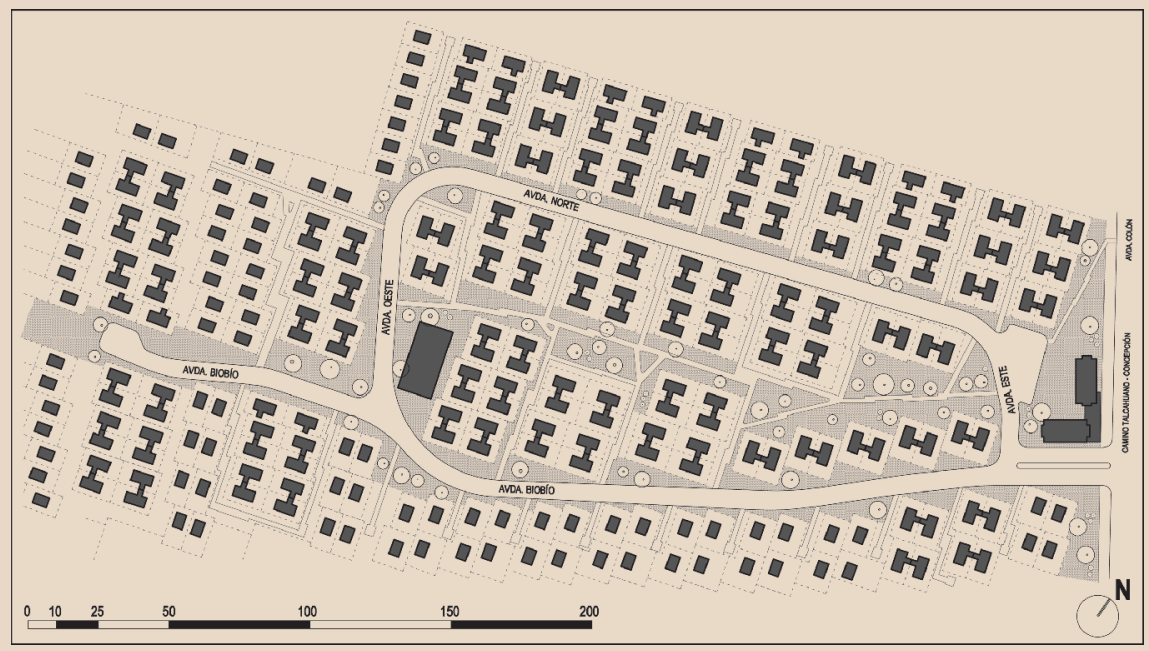

Figura 11. Santiago Roi y Ricardo Hempel. Villa Acero (1965). (Dibujo Francisca Valencia).

\section{URBANISMO INSTITUCIONAL. LA INTERVENCIÓN MODERNA EN LA CIUDAD}

A mediados de los años sesenta, el desarrollismo, proyecto económico latinoamericano creado en el seno de la creciente industrialización y urbanización continental, impuso la necesidad de un programa político de renovación. Se trataba de una ideología dominante que aspiraba alcanzar una sociedad moderna, calificada para garantizar el crecimiento económico y el equilibrio de las desigualdades sociales. En ese marco, el Estado favoreció las estructuras estatales con el objeto de organizar las áreas productivas y de servicios. Su papel se orientó a desarrollar importantes políticas de progreso urbano y habitacional.

En ese contexto, la política chilena estipuló que la vivienda era un derecho de primera necesidad al alcance de todo grupo familiar, por lo que el gobierno atendió especialmente los grupos de escasos recursos. La vivienda sería pagada total o parcialmente en su valor real, nunca regalada. Debería tener condiciones mínimas de superficie y calidad, con equipamiento indispensable para mejorar la vida familiar y el desarrollo comunitario. El programa gubernamental profundizó la racionalización de la producción 
habitacional regulando el mercado productor y organizando la demanda. Para el caso, se estrecharon los vínculos entre el desarrollo urbano y la política habitacional. En la práctica, en 1965 se promulgó la Ley 16.391 que creó el Ministerio de Vivienda y Urbanismo e hizo depender de éste a la Corporación de Servicios Habitacionales, CORHABIT; y a la Corporación de Mejoramiento Urbano, CORMU y reorganizó la CORVI y la Corporación de Obras Urbanas COU, todas instituciones que gozaron de gran autonomía. Asimismo, se creó el Banco del Estado como entidad de financiamiento público.

Así, durante los años sesenta en Concepción los proyectos de la CORVI apuntaban en cuatro direcciones: construir una extensa villa en San Pedro, al otro lado del río Bío-Bío, al poniente de la ciudad; extender una extensa área habitacional en el sector de Hualpencillo y concentrar otro grupo habitacional en el sector Higueras y Perales, ambos al norte de la ciudad; y en el centro remodelar nueve manzanas con nuevas soluciones habitacionales, llamada a la postre Remodelación Concepción, hoy Paicaví (Pacheco, 1997: 82).

Paralelamente, las inversiones privadas buscaban crear centros habitacionales en la periferia, con amplias áreas verdes. Bajo estas ideas se iniciaba en 1963 la Villa Acero, afianzando la expansión poblacional por el camino a Talcahuano (Pacheco, 1997: 84).

La CORMU gozó de una ley orgánica que le permitió adquirir terrenos y construir varios conjuntos relevantes. $\mathrm{Al}$ respecto, se le permitió renovar áreas deterioradas a través de programas de renovación urbana para impedir el crecimiento descontrolado de las ciudades adscribiendo los principios del urbanismo moderno. Esta ley la facultaba para cooperar y asociarse con municipios y empresas privadas en la elaboración de proyectos de desarrollo y mejoramiento urbano, conceder créditos para esos objetivos, supervisar y controlar su ejecución, establecer al interior de las zonas urbanas las áreas de mejoramiento y proponer su ordenamiento y progreso ${ }^{11}$. Entre sus facultades contaba con:

(...) mejorar y renovar las áreas deterioradas de las ciudades mediante programas de remodelación, rehabilitación, fomento, mantención y desarrollo urbano y asociarse con Municipalidades, empresas particulares

\footnotetext{
${ }^{11}$ Cfr. Artículo 2o del Título I de la Ley Orgánica de la Corporación de Mejoramiento Urbano, CORMU.
} 
u organismos públicos en la ejecución de proyectos de desarrollo y mejoramiento urbano y otras facultades ${ }^{12}$.

A partir de 1970 la CORMU tomó un papel activo en la gestión de complejos habitacionales. Estableció delegaciones en Arica, Valparaíso, Punta Arenas y Concepción (Ulloa y Uribe, 2009). En esta última ciudad, bajo la dirección del arquitecto Osvaldo Cáceres, tuvo una intensa actuación sola o con sociedades mixtas.

La CORMU, a través de distintos tipos de gestiones habitacionales, se ocupó de varios conjuntos en la región, remodelando importantes zonas urbanas. La mayoría de ellos optó por implementar los principios de los CIAM, pero prescindiendo de transformar la estructura urbana de damero tradicional de la ciudad; esto es, se mantuvieron las manzanas preexistentes y se insertaron en ellas, previa unificación de parte o la totalidad de sus solares, edificios aislados de 4 ó 5 niveles, con intenciones de formar un conjunto armónico que no necesariamente respetaba el paralelismo con los bordes urbanos.

Varias intervenciones habitacionales institucionales se dispusieron precisamente sobre aquellos ejes estructurales viales de la ciudad, acentuando, de este modo, la implantación concatenada de los conjuntos.

El fortalecimiento de la avenida Los Carrera en el centro de Concepción con una serie de conjuntos habitacionales durante el siglo XX ratificó la existencia de un eje nuclear del área metropolitana. Con el emplazamiento de las principales industrias el desarrollo urbano inició un proceso de crecimiento tentacular en el que cada apéndice admitió argollas interdependientes, formando cadenas cuyas direcciones y longitudes definieron varias rutas habitacionales.

$\mathrm{Al}$ respecto, es posible detectar otros cuatro ejes de transporte que confluyen sobre Concepción. El primero, parte por el norte, en el puerto de Talcahuano, y llega al sur hasta Concepción. El segundo, se puede reconocer entre esta ciudad y las localidades de Penco, Lirquén y Tomé. El tercero se prolonga desde Concepción por el borde fluvial del río Bío-Bío y se extiende hasta Chiguayante y Hualqui. Finalmente, el cuarto se desarrolla por la costa del Pacífico hacia Coronel, Lota y Lebu. Todas estas localidades estaban destinadas a consolidar un sistema productivo e industrial interactuante en la región.

12 "Remodelación San Borja”, AUCA, No 16, Santiago de Chile, ago-sep, 1969, s/p. 
Estos ejes de transporte admitieron aledaños a ellos una cantidad importante de conjuntos residenciales durante el siglo XX. Se trata de un sistema urbano que se fue consolidando a través de eslabones habitacionales. Eran asentamientos que propusieron una nueva lectura del espacio público y del funcionamiento del transporte vehicular cuyo principal resultado fue la desaparición de la calle corredor tradicional y la aparición de espacios verdes y recreativos como articuladores de los conjuntos. Este ordenamiento habitacional llegaría a ser característico del área metropolitana de Concepción hasta los años setenta y suturaba los espacios entre las localidades mencionadas. Se trataba de una ocupación que no afectó al paisaje natural de la zona, y por el contrario, prefirió supeditarse al desarrollo funcional ocupando zonas planas y valles.

\section{Eje Los Carrera}

En la Avda. Los Carrera se construyó en la esquina con calle Serrano un conjunto diseñado por Werner Stehr y Marcos Araya (Fig. 12). Se trata de la ocupación de media manzana por tres bloques compuestos (una versión mejorada del bloque 272 construido en la remodelación Eleuterio Ramírez, vista más adelante), en torno a un patio central que se abre a calle Serrano. Son edificios de 5 plantas que incorporan de forma particular una forma de mansarda en la planta superior. Para el caso, sin considerar equipamiento social, se han establecido áreas recreativas comunes.

Más al oriente, la Remodelación Paicaví (1965) fue gestionada por la CORVI a través de un concurso nacional ganado por S. González, P. Iribarne, G. Mardones, J. Mardones y J. Poblete. Constituye uno de los ejemplos de remodelación urbana mejor logrado. Originalmente se trataba de la renovación de 18 manzanas próximas al centro de la ciudad comprendidas entre las calles Bulnes, Galvarino, Los Carrera y Tucapel. Su primera etapa consideraba la intervención sobre 9 manzanas. El conjunto fue concebido como dos supermanzanas divididas por la Avda. Paicaví, unidas por un puente peatonal sobre esta arteria. La del lado oriente, la única construida en ese momento, estaba compuesta por tres manzanas tradicionales y la del lado poniente por seis. Era una composición apegada a los fundamentos de la Carta de Atenas. 


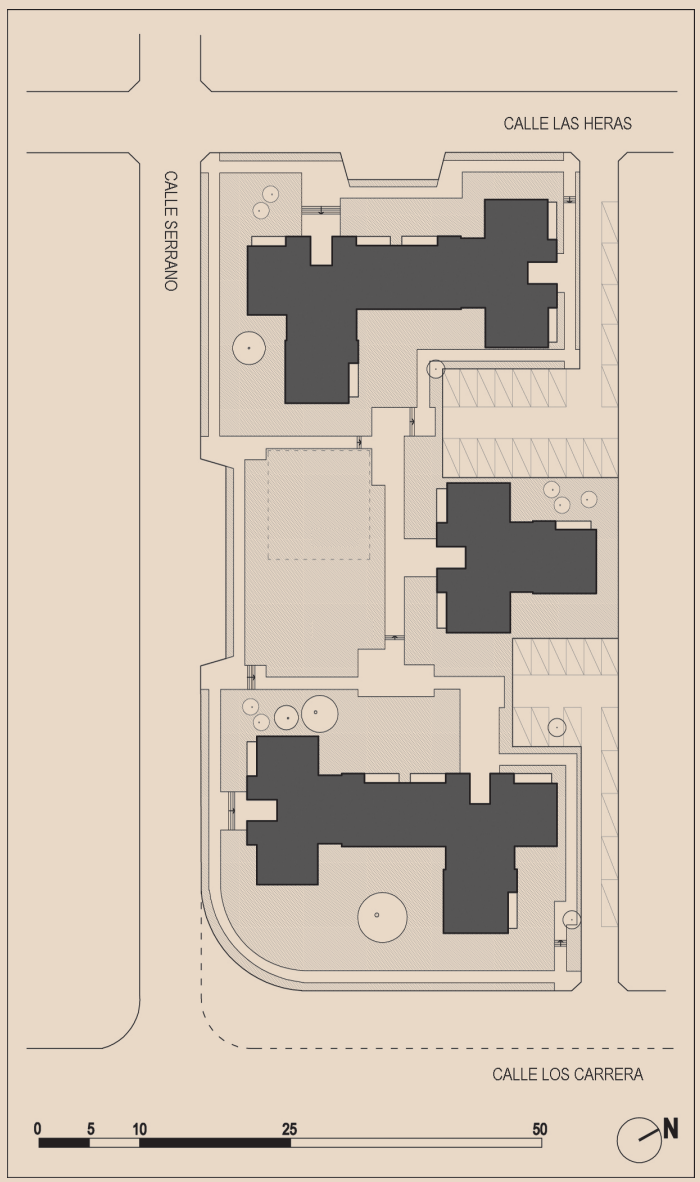

Figura 12. Werner Sther y Marcos Araya. Conjunto Los Carrera esq. Serrano (1978). (Dibujo Brogan Ulloa y Ronald Uribe).

Dejaba en sus bordes las circulaciones vehiculares y en su interior las peatonales. Asimismo, dispersaba los cuerpos sobre amplias áreas verdes. No obstante, el trazado general mantenía una suerte de trama virtual, eco de las manzanas tradicionales preexistentes, que a la postre sirvió para organizar subvecindarios menores. 
En principio, el proyecto consideraba una zona comunitaria en el centro del conjunto que incorporaba un área cívica (plaza, escuela, supermercado, locales comerciales, teatro, biblioteca, administraciones, etc.) y el puente de conexión entre ambas supermanzanas. Este sector estaría significado por una torre de 16 plantas de altura.

La zona residencial contemplaba vecindarios para unas 210 viviendas cada uno (1.200 habitantes) dotados de servicios menores (locales comerciales, juegos infantiles, estacionamientos). El sistema vial principal rodearía la unidad estableciendo penetraciones para abastecimiento comercial, servicios y estacionamientos. Su organización se oponía a la trama tradicional, cuestión establecida en la memoria del proyecto cuando se refiere al tratamiento espacial.

En oposición a la solución tradicional, que implica la construcción continua de la periferia de la manzana, y que genera la calle como elemento único del paisaje urbano, se ha concebido un sistema volumétrico que libera el centro de la manzana y lo incorpora al uso urbano como área recorrible ${ }^{13}$.

En cuanto a los edificios, el proyecto original disponía cuatro tipos de volúmenes (2, 4, 5 y 16 niveles) organizados bajo nuevas concepciones espaciales.

(...) las áreas de esparcimiento, las repeticiones rítmicas, etc., se han trabajado de manera de obtener una solución, recontinuidad y fluidez en las áreas recorribles, enriquecidas, además, por la variedad de los elementos que conforman las perspectivas ${ }^{14}$.

A la postre, como se ha dicho, sólo se construyó la supermanzana oriente confinada entre las calles Bulnes, Janequeo, Los Carrera y Paicaví (Fig. 13) aunque se mantuvieron las características urbanas originales. En cuanto a los edificios, los hubo de cuatro tipos: dos longitudinales y dos de planta cuadrada. El primero fue un cuerpo longitudinal con escaleras y circulaciones externas de cinco alturas, que tiene en su primer nivel viviendas de una planta y hacia arriba dos dúplex. El segundo, con escaleras internas de cuatro alturas, es también longitudinal, pero de una planta por nivel con un acceso exterior albergado por un cubo virtual. Ambos son correspondien-

\footnotetext{
13 “Remodelación Concepción”, AUCA, No 15, jun-jul, 1969, p. 68.

${ }^{14}$ Ibídem.
} 
tes con la ortogonalidad de la supermanzana. El tercer tipo fue un cuerpo cuadrado de cuatro alturas, con el núcleo de circulaciones y patio al centro, y cuatro departamentos por nivel. Éstos fueron organizados en grupos de tres y puestos en diagonal respecto a la trama. El cuarto correspondía a dos edificios de cuatro niveles, inscritos en un cuadrado diagonal a la trama, articulados por las escaleras y patio de acceso, cada planta de cada edificio tiene dos departamentos, en suma, cuatro por nivel. Todos cuentan con una acentuada separación espacial entre ellos ocupada por áreas verdes, desconocen la continuidad de las fachadas y manifiestan, como conjunto, una magnitud mayor a la tradicional.

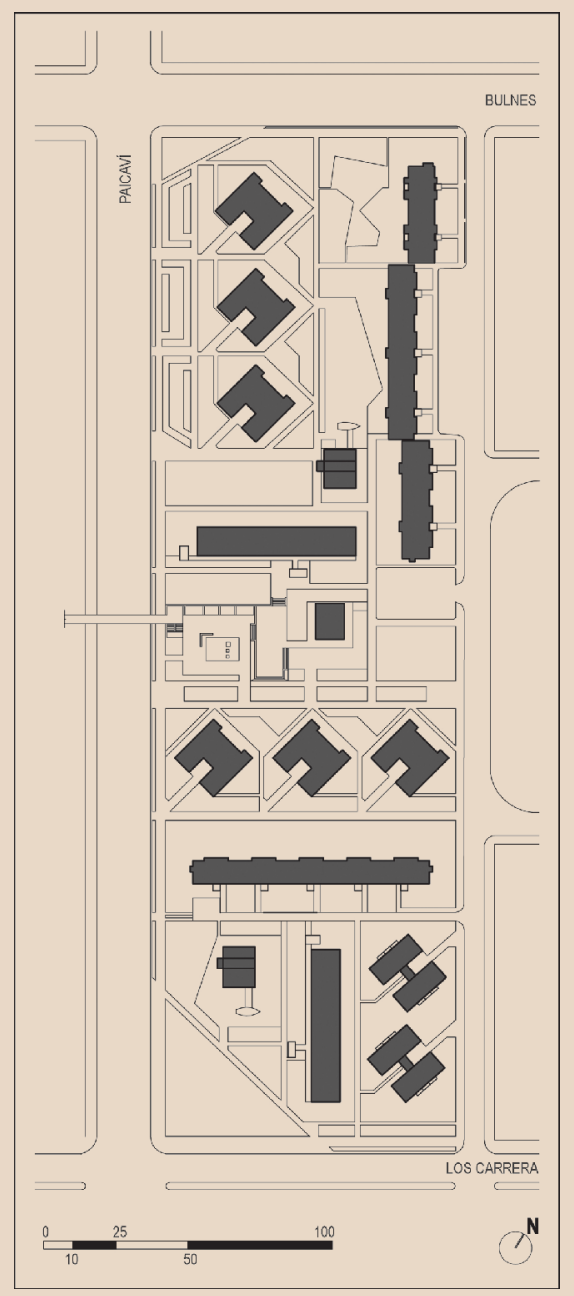

Figura 13. TAU: Sergio González, Pedro Iribarne, Gonzalo Mardones, Julio Mardones, Jorge Poblete (17/06/1950). Remodelación Paicaví (1965). (Dibujo Pablo Miranda y José de la Rosa). 
Siguiendo con la regeneración de partes de la ciudad, la Remodelación Eleuterio Ramírez (1977) (Fig. 14), un seccional de CORMU prosiguió con la modalidad establecida en la Remodelación Paicaví. En este caso, aunque no se siguió con el plan establecido originalmente por TAU para el sector, la gestión de tres manzanas paralelas a la Remodelación Paicaví comprendidas entre las calles Ongolmo, Bulnes, Paicaví y Los Carrera insistió sobre la unificación de estas manzanas en una sola unidad. En este caso se ubicaron bloques estandarizados alternados que consiguieron recuperar virtualmente los bordes urbanos, y dejaron grandes áreas de jardín y patios interiores públicos, controlados y resguardados que estimulaban la vida recreativa y comunitaria. En este caso, las tipologías usadas fueron el bloque 871 y el 172 de cuatro plantas diseñado por Eduardo Ortiz. Finalmente, en la esquina de Avda. Los Carrera y Ongolmo, otro bloque único diseñado por Carlos Mardones Santiestevan completó el conjunto. Esta ocupación fue abortada con el golpe militar y los trabajos fueron reanudados posteriormente por el SERVIU en 1977 mediante un seccional desarrollado por Werner Stehr, que incluyó otro tipo edificatorio, el bloque 272. Su ubicación, preferentemente en el centro de la macromanzana, completaba la intervención general sobre esta macrocuadra.

A la salida de Concepción, en la prolongación oriente del eje Los Carrera, la Avda. Irarrázaval, y siguiendo con la idea de asentar grandes conjuntos habitacionales que configuraran esta vía, en la manzana aledaña al oriente del Hospital del Trabajador, conformada por la Avda. Irarrázaval, las calles Baquedano, L. Arenas y Diego de Oro, se distinguen tres conjuntos habitacionales, separados por el pasaje Perelló Puig.

El primero de ellos es el conjunto SERVIU (1976) que se instaló en la manzana comprendida entre dicha avenida y las calles Baquedano, Lorenzo Arenas y el pasaje Perelló Puig (1976) (Fig. 15). Se trata de una unidad proyectada para el SERVIU por Víctor Lobos Lápera de cinco bloques paralelos y aislados, orientados de norte a sur. Los bloques de 4 niveles, compuestos por departamentos dúplex, se alternaron reconociendo virtualmente los bordes del terreno, cuestión a la que en el proyecto se sumaba equipamiento social y de comercio, formando entre todos patios interiores que fomentaban la vida comunitaria.

En el costado oriente el segundo conjunto, proyectado por Mario Gómez para la Caja de Previsión de la Defensa Nacional, CAPREDENA (Fig. 16) está compuesto por bloques de 5 pisos, cercanos en sus vértices, que fueron emplazados en dirección norponiente-suroriente. Finalmente, dos bloques aislados en dirección norte-sur terminan por conformar la manzana. Las áreas verdes exteriores articulan la totalidad. 
Figura 14. SERVIU; Werner

Stehr. Seccional Eleuterio Ramírez. (Dibujo Brogan Ulloa y Ronald Uribe).

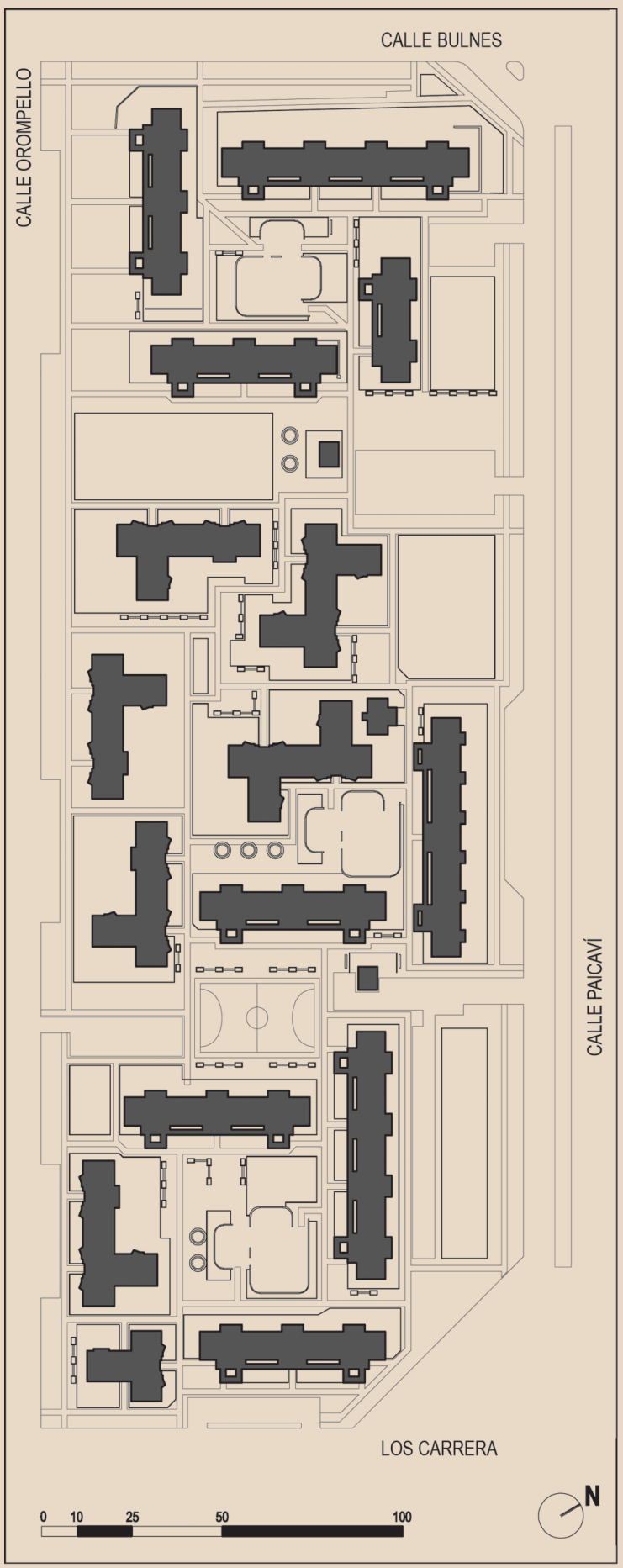



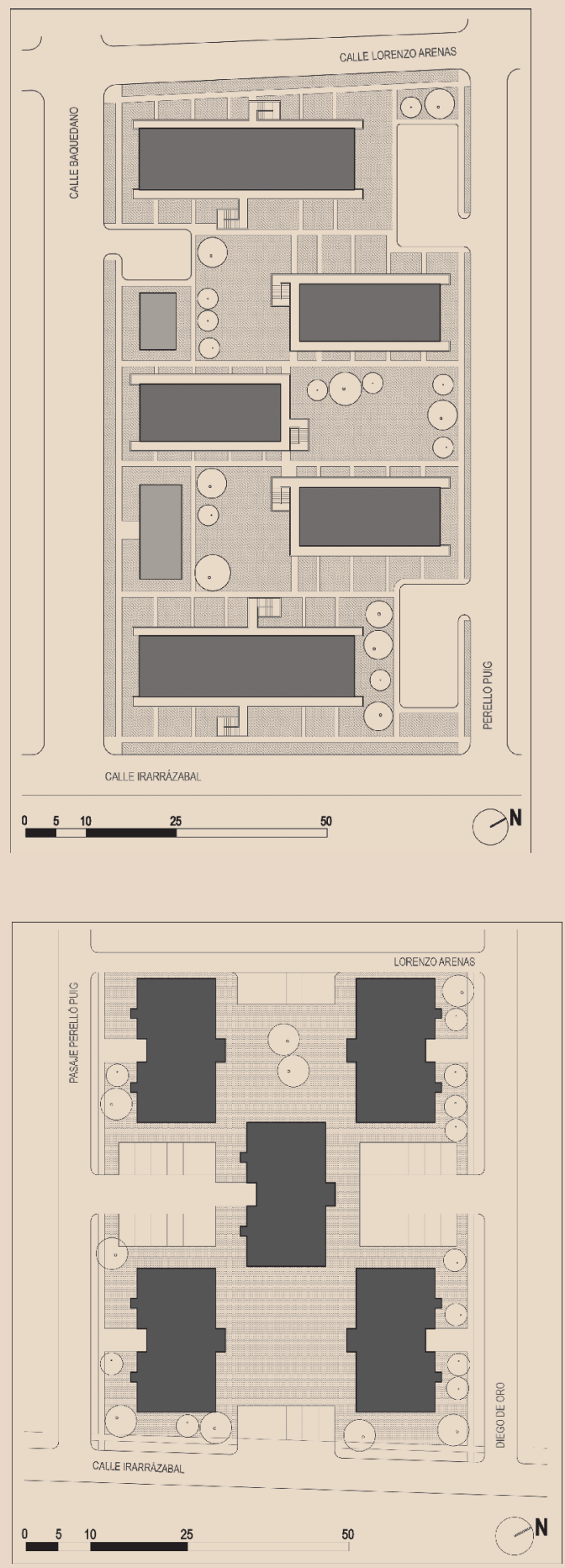

Figura 15. SERVIU; Víctor Lobos Lápera. Conjunto Baquedano, Lorenzo Arenas y Pasaje Perelló Puig (1976). (Dibujo Francisca Valencia).
Figura 16. CAPREDENA; Mario Gómez. (Dibujo Francisca Valencia). 


\section{Eje Concepción - Talcahuano}

Ubicado un poco más al norte del conjunto Lorenzo Arenas, ya mencionado, se desarrolla el Grupo Habitacional Ramón Freire (1961) (Fig. 17) encargado por CAPREDENA a los arquitectos Mario Gómez y Jorge Ábalos. Ubicado al poniente del eje 21 de Mayo, se trata de un diseño más ortodoxo desde el punto de vista de la disposición volumétrica funcionalista. Se compone de seis bloques longitudinales de 5 niveles, orientados en dirección nororiente-surponiente distribuidos desfasados y en paralelo sobre un amplio terreno destinado a áreas verdes que dejaba en sus bordes oriente y sur la circulación vehicular. Esta distribución impedía la formación regular de patios interiores, privilegiando la continuidad del espacio como valor propio de las aspiraciones higienistas en cuanto a asoleamiento y ventilación de los cuerpos arquitectónicos.

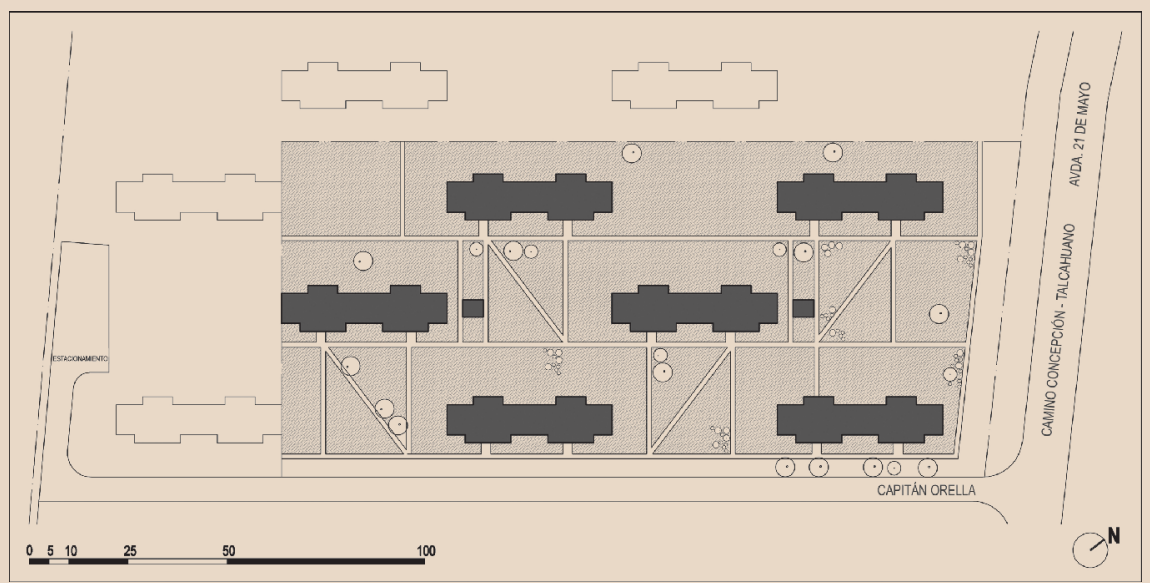

Figura 17. CAPREDENA; Mario Gómez y Jorge Ábalos. Grupo Habitacional Ramón Freire (1961). (Dibujo Francisca Valencia).

La Población René Schneider (1968) (Fig. 18) promovida por la CORVI se ubica en la comuna de Hualpén, al costado oriente de la Avda. Colón. Se trata de un conjunto que mezcla dos opciones urbanísticas: la disposición de bloques 1010-B junto a la avenida, y posterior a esta franja, la organización de micromanzanas en torno a pequeñas plazas. La primera decisión se 
ha dispuesto siguiendo el emplazamiento tradicional del urbanismo moderno, es decir, bloques aislados ubicados sobre lo que se esperaba fueran áreas verdes y caracterizando un espacio particular del nuevo asentamiento. La segunda elección vuelve sobre disposiciones que reinterpretan la manzana y el damero cuyas dimensiones y vacíos estimulaban el encuentro comunitario.

Más al norte, un amplio sector habitacional auspiciado por la CORMU fue erigido en las inmediaciones del antiguo aeropuerto de la zona, que funcionó entre 1941 y 1967, donde a partir del diseño de Eduardo Ortiz se

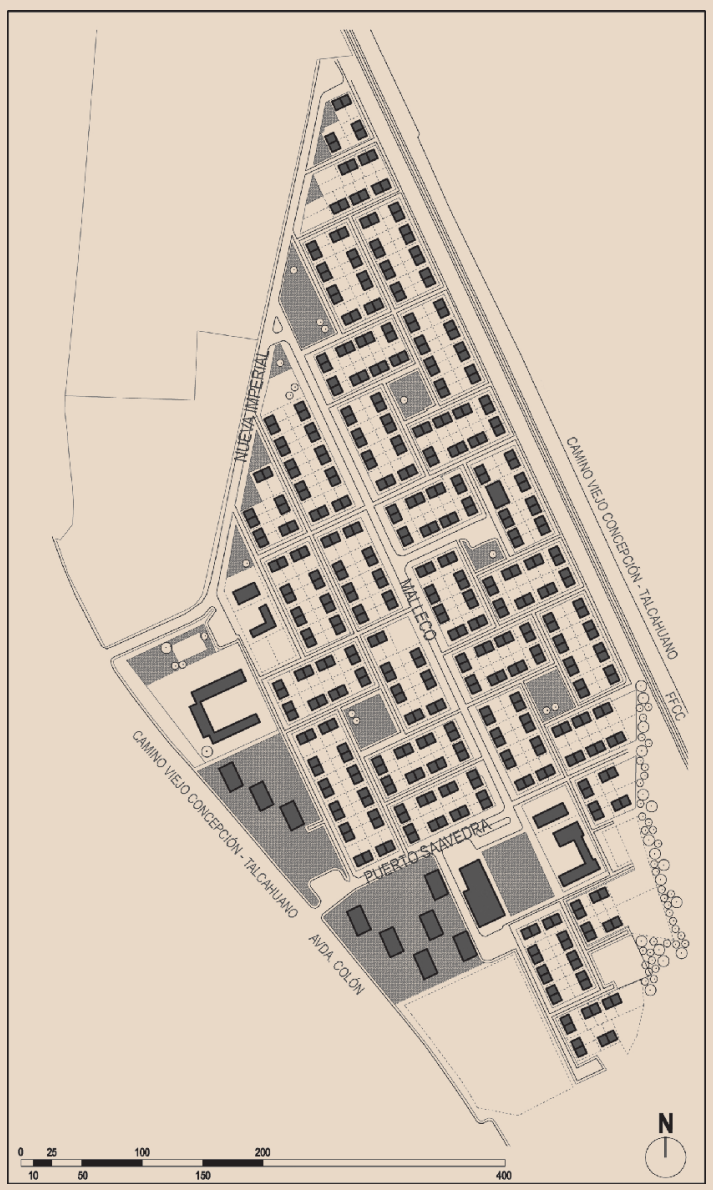

Figura 18. CORVI; Población René Schneider (1968). (Dibujo Francisca Valencia). 


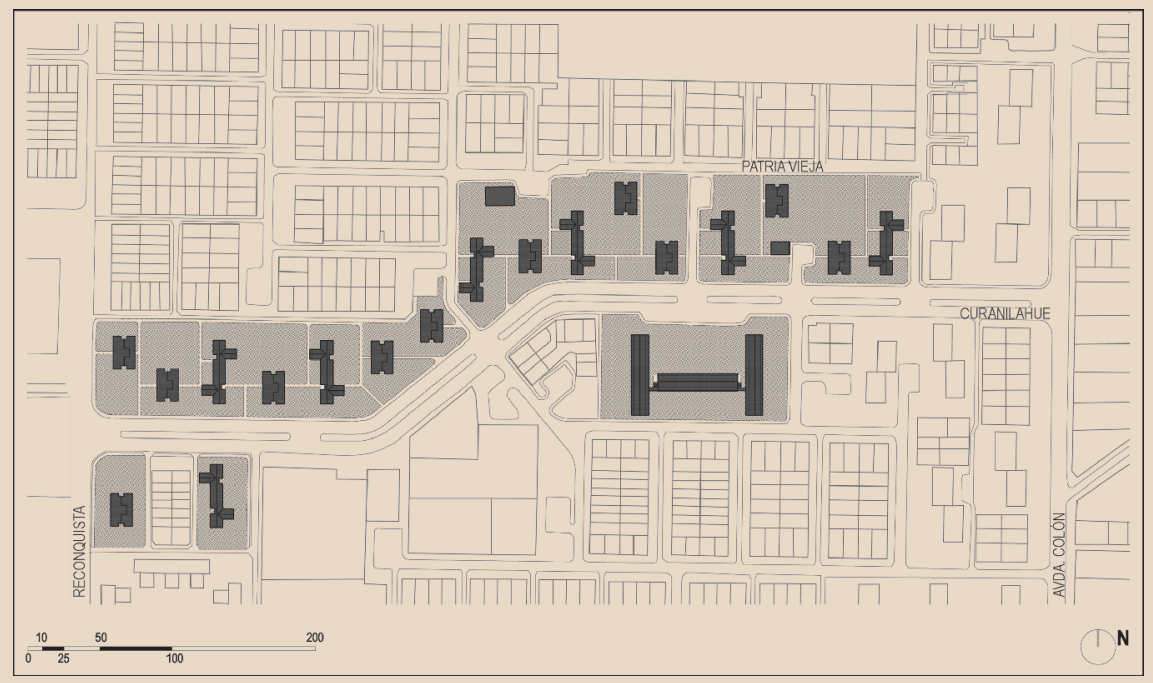

Figura 19. CORMU; Eduardo Ortiz. Seccional Hermanos Peredo. (Dibujo Brogan Ulloa y Ronald Uribe).

construyó el seccional Hermanos Peredo (Fig. 19), sobre la avenida Curanilahue, perpendicular al eje vial, terreno que por años perteneció a la circunscripción de la comuna de Talcahuano, hoy parte de Hualpén. Consta de 3 tipos de edificios: el bloque tipo A, 11 edificios, de Gabriela González, Roberto Goycoolea, Ernesto Vilches y Luis Soto; el bloque tipo B, 7 edificios, de Jorge Labarca y Jorge Harris y el bloque tipo C, 3 edificios, proyectado por Eckart Lengerich y Guido Briceño. El emplazamiento de cuerpos aislados, dispersos sobre grandes superficies de terreno que se suponían destinados a áreas verdes, revelan una adscripción dogmática y tardía a los planteamientos de la ciudad funcional. La baja calidad arquitectónica, la desproporcionada distancia entre los volúmenes y la carencia de posibilidades socioeconómicas de sus habitantes ha hecho imposible un sentido de pertenencia del espacio público y ha promovido el cuestionamiento de una de las mayores operaciones inmobiliarias destinada a las necesidades sociales de esa época.

Su expansión mediante otros grandes paños urbanizados durante los años ochenta y noventa determinaron un sector que ha tendido a consolidar la mancha urbana generada por las ciudades de Concepción y Talcahuano. La magnitud de su superficie y de su población ha promovido que en 2006 se independizara de la administración de Talcahuano y diera origen a la comuna de Hualpén. 
Otra intervención en el marco de la implantación de bloques aislados fue la Remodelación Simons (Fig. 20) en Talcahuano desarrollada por la CORVI a comienzos de los años 70, ocupando uno de sus modelos prototípicos, el Colectivo 1020. Ubicada frente al estadio de la ciudad, sobre un terreno de forma irregular, configura con el cerro El Morro una puerta urbana al puerto. $\mathrm{Al}$ igual que sus congéneres en otras ciudades, se organizó la distribución de sus volúmenes en una posición de norte a sur, alternando el vacío y cuerpos con el objetivo de permitir la higienización natural del sector, esto es partes ventiladas y asoleadas entre cuyos intersticios se distribuyen abiertas y sin control las áreas verdes. En su centro se ubicó un edificio de equipamiento como parte de los servicios públicos de la unidad. Una disposición volumétrica de este tipo aledaña al eje conector imponía un cambio de la percepción del espacio público.

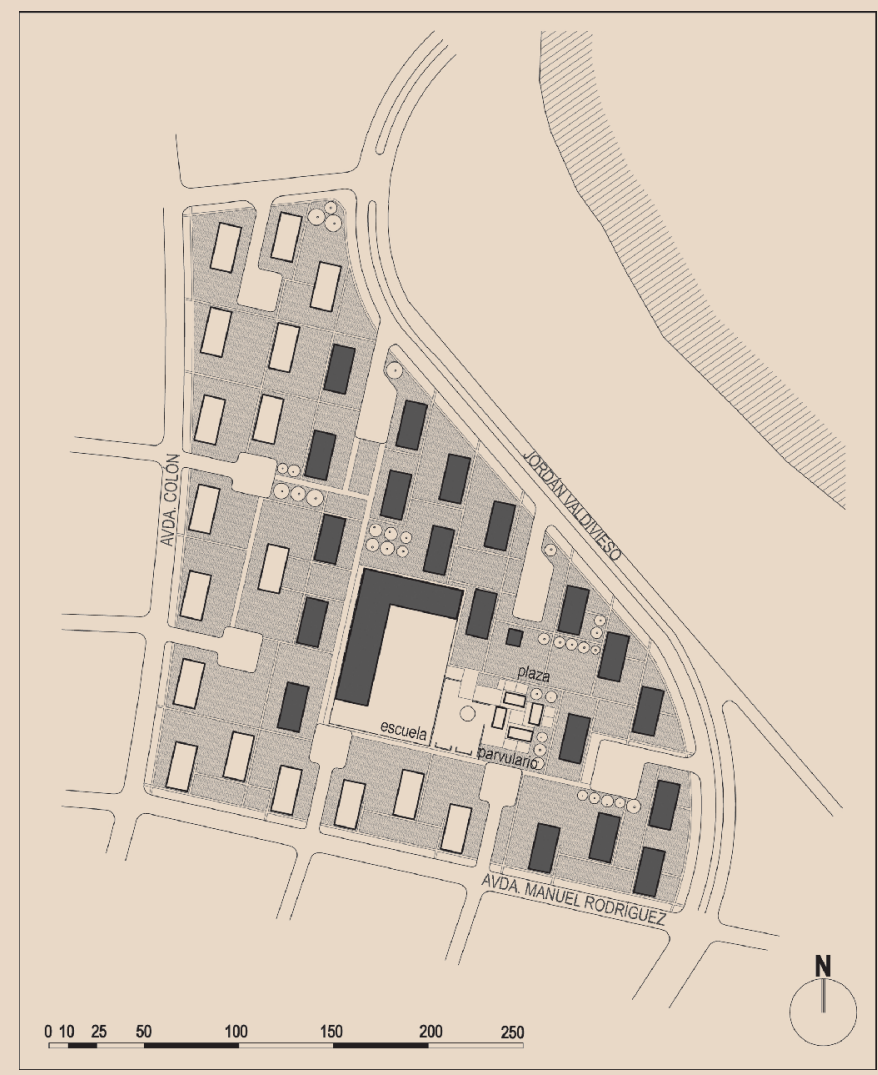

Figura 20. CORVI. Remodelación Simons. (Dibujo Francisca Valencia). 
Durante los años 70, en el centro de la ciudad de Talcahuano se realizó una de las últimas operaciones habitacionales realizadas en la región en el centro de la ciudad. La Remodelación Blanco (Fig. 21) fue una de las últimas intervenciones sobre el casco central de la ciudad. La intervención se desarrolló sobre dos manzanas separadas. Una se instaló sobre la comprendida entre las calles Colón, San Martín, Blanco Encalada y Bulnes; una manzana de por medio más al sur, la otra se desarrolló sobre el predio formado por Colón, Covadonga, Blanco Encalada y Esmeralda.

Figura 21. Remodelación Blanco. (Dibujo Francisca Valencia).

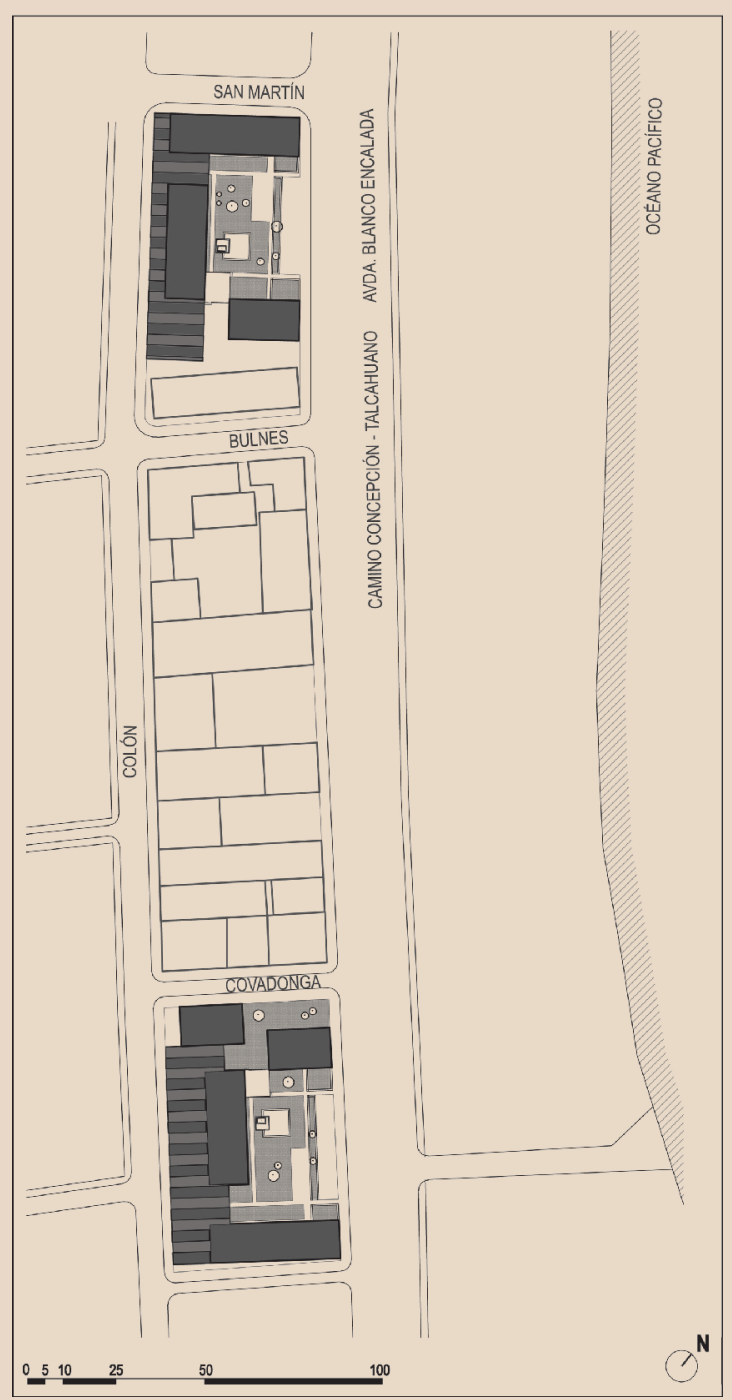


El proyecto consistió en bloques de 5 niveles. La preocupación por mantener la fachada continua a nivel peatonal por la calle Colón, una de las principales arterias comerciales de la ciudad, caracteriza la organización. Para el caso, una placa continua de un nivel, cubierta por techos plegados a dos aguas incorpora hacia la calle mencionada un nivel comercial de una planta cuyo alero cobija al peatón de las inclemencias del clima. Detrás de ella se dispusieron aislados tres bloques de diversos tamaños y orientaciones. En la primera manzana, por problemas de parcelación del predio, un único bloque ocupa el borde a la calle Bulnes. En su conjunto, se trata de un proyecto del que se distinguen dos peculiaridades. Una muestra la disposición a modificar un área mayor del centro de la ciudad a través de una solución funcionalista uniforme; otra, el reconocimiento que este urbanismo funcionalista abandonaba su sentido dogmático para incorporar valores del urbanismo tradicional como la fachada continua y el cobijo del peatón.

\section{Eje Concepción-Penco}

Otro conjunto que ha contribuido a configurar este eje metropolitano, al norte de la cárcel El Manzano, es la Villa Universitaria diseñada por el arquitecto Emilio Duhart. Está organizado por manzanas y pasajes ocupados por viviendas unifamiliares de un nivel que abrazan un espacio verde interior destinado a la recreación.

En Penco, la ubicación del mismo bloque diseñado por Ramón Jofré y Eduardo Ortiz desarrollado para Lota Alto, ocupa parte de una manzana, dejando a su alrededor unas áreas de control impreciso.

La Remodelación Ñancahuazú, actualmente Lord Cochrane, agenciada por la CORMU, diseñada por los arquitectos Hugo Campos y Orlando Paredes en el centro de la manzana de calle El Roble, Lord Cochrane, Yerbas Buenas y la línea férrea, en Penco, al igual que en Lota Alto, concilia los dos tipos de edificios, el 171 y el 271, emplazados de norte a sur.

En la misma ciudad, en la esquina de las calles Infante y Blanco, y también gestionada por la CORMU, se ubicó la Remodelación Lautaro, mediante tres edificios del bloque 871, diseñado por Eduardo Ortiz, formando un patio interior.

\section{Eje Concepción - Hualqui}

Para el caso, se trata del eje menos intervenido institucionalmente a partir 
de la década de los años 50. En este caso, su desarrollo en microvalles por asentamientos privados lo desprende de la condición general de la ciudad.

\section{Eje Concepción - Lota}

La Villa San Pedro (1961) (Fig. 22) constituye una intervención habitacional de gran magnitud en el Área Metropolitana de Concepción. Fue proyectada para la CORVI por los arquitectos Raúl Farrú, Roberto Merino y Enrique Porte. Se emplazó en un terreno a la orilla sur del río Bío-Bío, en un sector aledaño al camino que unía Concepción con Coronel y Lota y que está entre la Laguna Grande y la Chica, y entre cerros que enriquecían el paisaje.

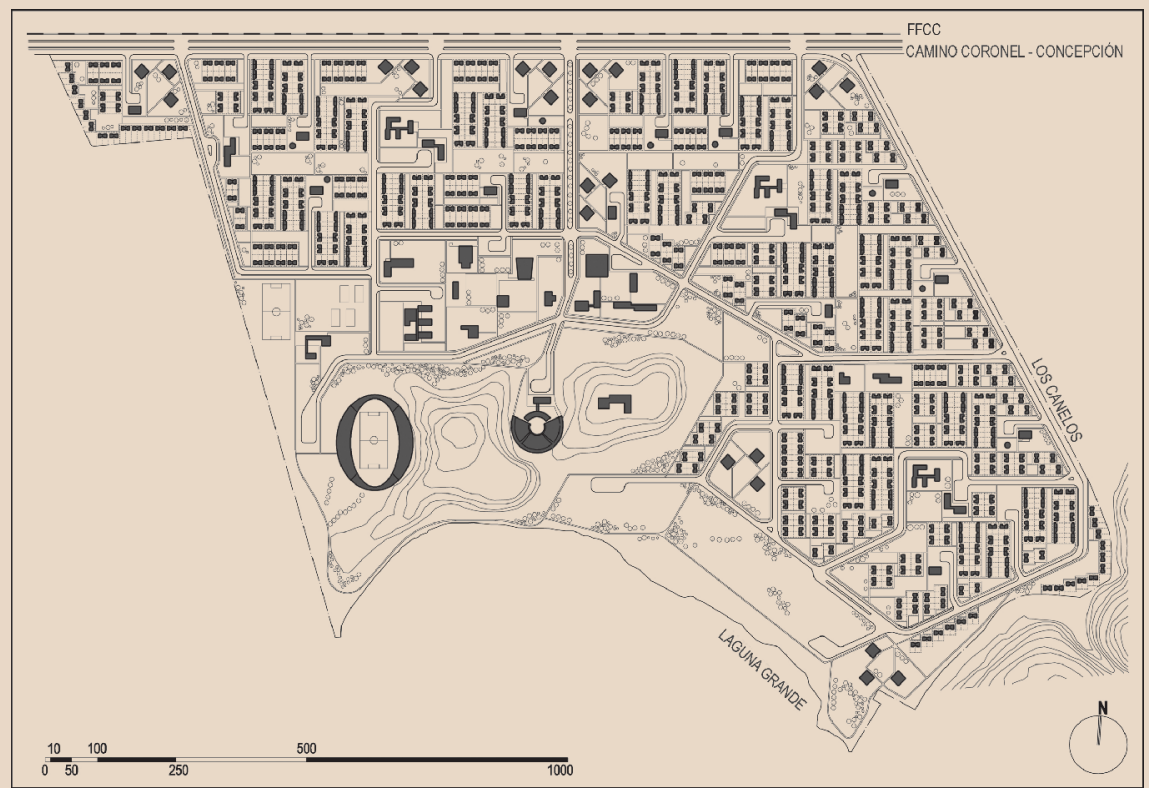

Figura 22. CORVI; Raúl Farrú, Roberto Merino, Enrique Porte. Villa San Pedro (1961). (Dibujo Francisca Valencia).

Por el particular entorno geográfico de la ciudad de Concepción, la CORVI se enfrentaba a la escasez de terrenos de bajo coste, cuestión que la obligó a buscar posibilidades en la periferia de la ciudad. Finalmente, hacia 
el sur, al otro lado del río, la institución consideró un terreno de 153,49 ha. Aunque el sector pertenecía a la comuna de Coronel, estaba ubicado a más de 35 kilómetros de esta ciudad. Por su ubicación la CORVI consideraba al futuro asentamiento como alternativa de crecimiento periférico de la ciudad de Concepción.

Es una intervención urbana de grandes proporciones emplazada tangencial a uno de los ejes viales y productivos más importantes de la región. Se trata de la vía costera que une Concepción con Coronel y Lota, hasta extenderse a la zona minera y forestal de Arauco. Su papel consolidaba un tipo de modalidad urbana característica de la zona que organizaba asentamientos habitacionales adyacentes al eje como forma de complemento a la producción industrial. Esta cuestión queda ratificada en la cercanía y complementariedad de la Villa con dos industrias construidas apenas unos años antes: Papeles Bío Bío, empresa de la Compañía Manufacturera de Papeles y Cartones (CMPC), fundada en 1957 para producir papel de periódico, y de la planta de producción de asbesto cemento Pizarreño creada en 1962.

El proyecto Villa San Pedro se concibió como un gran barrio residencial con las propiedades de la ciudad-jardín, planteado como "una solución que preserve la belleza del parque a través de la planificación libre con amplias áreas verdes y una faja de parques de 150 metros de ancho junto a la laguna" (CORVI, 1961). De las 153,4 hectáreas, 38,5 son cerros cubiertos con bosques y 16,3 hectáreas de parques, o sea, en total, el 35,7\% del conjunto son áreas verdes ${ }^{15}$.

Estaba organizado entre una avenida de circulación principal en el borde norte y otra menos importante en el límite oriental. La estructura general dispuso tres grandes sectores que agrupaban unas 600 viviendas y que están relacionados con un núcleo central que disponía de un centro cívico de servicios que comprendía: instalaciones comunitarias como bomberos, mercado, teatro, centro social, consultorio médico, escuela, iglesia, etc. Cada sector contenía pequeños vecindarios compuestos por 70 a 80 viviendas ordenadas en torno a una pequeña plaza donde se ubicaba un parvulario y un pequeño comercio. Más al sur se disponía un parque recreativo bordeando a la laguna que remataba al poniente en un pequeño cerro en cuya cumbre se disponía una hostería y en sus ensenadas al norte un teatro al aire libre y un estadio. Desde las vías de borde se generaban ave-

\footnotetext{
${ }^{15}$ Los sitios con viviendas cubren 90 hectáreas, el centro cívico 12 hectáreas y el centro deportivo 7. Las viviendas unifamiliares, como tal, cubren 46,7 hectáreas, o sea el 30,4\% de la superficie total (Franck y Pérez, 2009).
} 
nidas y pasajes de penetración. Las avenidas de acceso aparecían señaladas por conjuntos de bloques aislados de cuatro plantas de altura. Desde esos puntos se organizaba una red compleja de pasajes y plazas interiores sucesivas donde se instalaban las viviendas. Estas vías están afectadas por la falta de continuidad espacial y son carentes de hitos referenciales, cuestiones que complican los recorridos internos.

Un aspecto claramente reconocible en la estructura urbana es la aplicación de los principios urbanos de la unidad vecinal ${ }^{16}$, principios aplicados frente a los temas de viviendas, servicios y entorno, tanto para circulación peatonal y vehicular como de permanencia, y que son reconocibles simultáneamente a distintas escalas. De esta forma se reconoce una escala mayor en las tres áreas y el centro cívico, después, una inferior en cada área y, finalmente, en cada subárea o vecindario.

Otro aspecto identificable fue la conformación de una estructura viaria claramente jerarquizada, donde se conformó un sistema de perímetros estructurantes y una red de vías de penetración, entre las que cuentan calles interiores que cruzan por el centro cada unidad y pasajes en cul de sac.

Por último, se diseñaron casas y edificios estandarizados que dieron una imagen homogénea a todo el conjunto. Las viviendas eran piezas pareadas de uno y dos niveles, diseñadas con variaciones tipológicas, y los bloques eran cuerpos cuadrados de cuatro plantas a distinto nivel entre ellas, organizadas por una escalera interior.

A la postre el centro cívico no se construyó y su terreno fue ocupado por más viviendas y pasajes que imposibilitaron establecer una jerarquía espacial al conjunto. El resultado fue un complejo urbano de difícil comprensión espacial, aunque sus propiedades de ciudad jardín han sido exitosas.

El eje costero que nacía por el sur en Lota y que se prolongaba hasta Concepción, paralelo al mar Pacífico, incluyó otra serie de conjuntos diseñados a partir de los años sesenta.

El conjunto Camilo Olavarría, situado en una zona industrial con alta demanda habitacional en las afueras de la ciudad minera de Coronel, constituye uno de los casos más paradigmáticos en la configuración de este eje metropolitano, conformado por bloques de edificios y viviendas unifamiliares de un piso.

En Lota Alto, el Seccional Baldomero Lillo (Fig. 23) (1973), uno de los proyectos más grandes e importantes, ocupó el sector sur del eje vial Carlos Cousiño, en la cima del cerro. Su diseño estuvo en manos de Ramón Jofré

\footnotetext{
${ }^{16}$ Ibídem.
} 


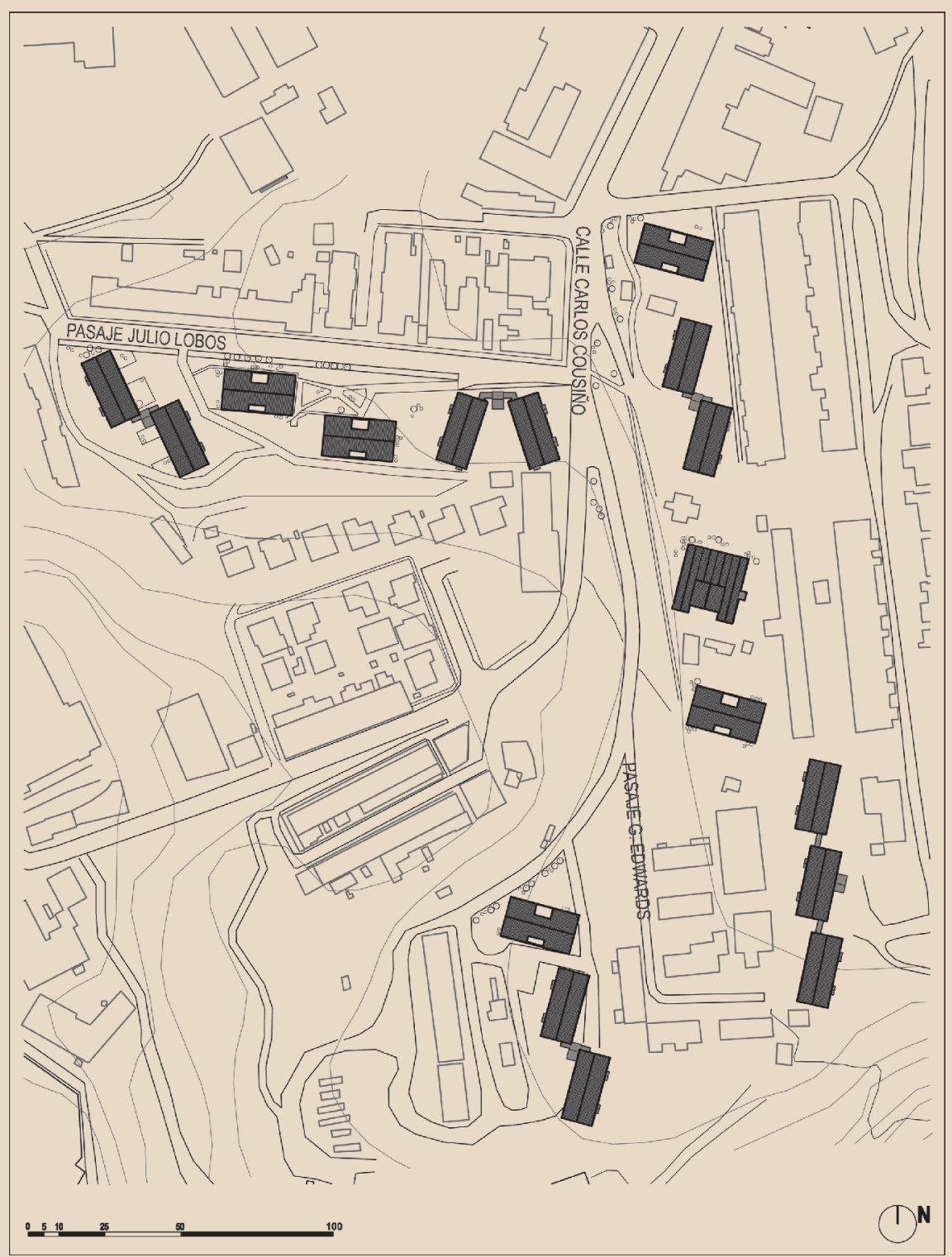

Figura 23. CORMU; Ramón Jofré y Eduardo Ortiz. Seccional Baldomero Lillo, Lota Alto (1973). (Dibujo Brogan Ulloa y Ronald Uribe). 
y Eduardo Ortiz por encargo de la CORMU. Para el caso, arquitectos más sensibles al valor de la imagen tipológica diseñaron dos tipos de bloques para vivienda colectiva que referían a los antiguos pabellones para los mineros del carbón. El emplazamiento de los edificios, consecuente con la orografía del sector, hace de esta intervención un ejemplo que articula sus aspiraciones modernizadoras con determinantes locales de arraigo formal, cultural y social. En esta oportunidad se trata de un conjunto de organización volumétrica y espacial disgregada, cualidad que, como se ha dicho, se sumó a la tipología existente. La organización consideró tres tipos de edificios, el bloque 171 de Eduardo Ortiz, el 271 de Ramón Jofré, ambos de 4 plantas y el 371 también de R. Jofré de 6 plantas. Estos dos últimos, los mejor logrados, se caracterizan porque en los niveles $1^{\circ}, 3^{\circ}$ y $5^{\circ}$, junto a su pasillo lateral de circulación, origina por su exterior escaleras que alcanzan individualmente a los departamentos del $2^{\circ}$ y $4^{\circ}$ y $6^{\circ}$ nivel. La proporción y el lenguaje de sus fachadas remiten a los pabellones existentes. Si bien la mayoría no organizó espacios públicos comunes, al menos un par se dispuso formando un patio compartido.

Casi en paralelo, la Remodelación Matías Cousiño (1966) (Fig. 24), un encargo de la CORVI destinado a imponentes de la Caja de Empleados Par-

Figura 24. Alejandro Rodríguez. Conjunto en calles Pedro Aguirre Cerda y Aníbal Pinto, Lota Bajo. (Dibujo Francisca Valencia).

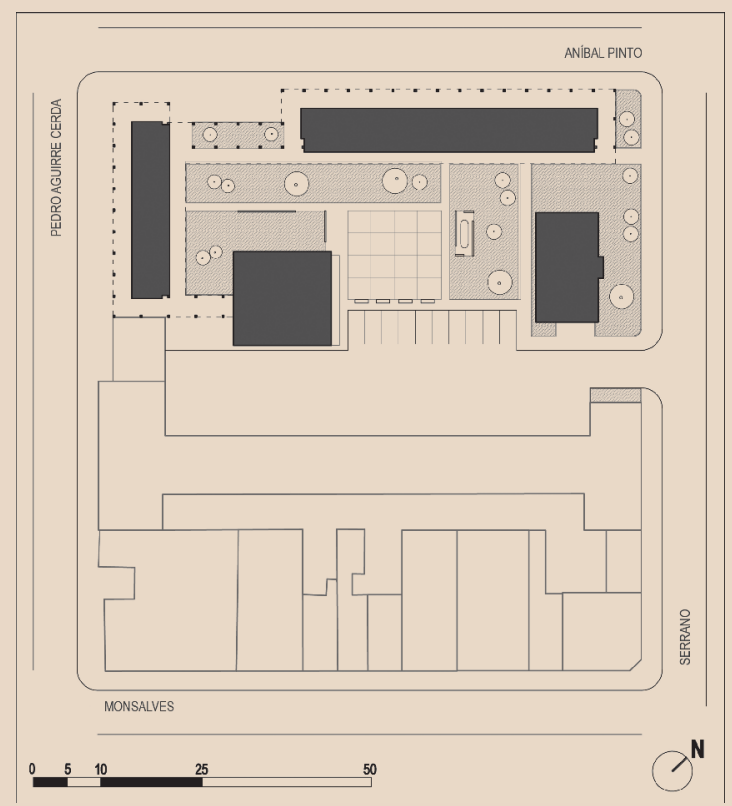


ticulares, ubicado en las calles Pedro Aguirre Cerda y Aníbal Pinto, en Lota Bajo, diseñado por Alejandro Rodríguez, realizó un tipo de solución similar al integrar al plan de damero unos bloques que de la misma manera remitían, acaso de forma más abstracta, a los pabellones mineros. En este caso, edificios, paralelepipédicos de hormigón, de 5 plantas, dejaron en el primer nivel, hacia la calle, portales de circulación. Hacia su interior conformaron un amplio espacio interno con el existente edificio Matías Cousiño ${ }^{17}$. Esta forma de remodelación, que reconocía los bordes de la trama tradicional de la ciudad, operó trasladando una tipología propia del campamento minero aledaño al centro de la ciudad.

\section{OCUPACIÓN DE LAS PENDIENTES. PUNTO DE INFLEXIÓN DEL DESARROLLO URBANO RESIDENCIAL}

Hacia el final de los sesenta una intervención que marca un punto de inflexión respecto de la modalidad de emplazamiento, hasta cierto punto ya tradicional, de ubicarse en zonas bajas, la constituye la del barrio El Golf (1969) (Fig. 25), más conocido como Laguna Redonda. Es un conjunto habitacional originado de las políticas del SERVIU. Se trató de la instalación de unos 50 bloques 1020, 12 de ellos adosados por su lado menor, sobre el cerro el Golf, al oriente de la Laguna Redonda, hito geográfico del sector, y ubicados en dirección norte-sur. Los cuerpos ocupan las cumbres del cerro y fueron desfasados y distanciados entre ellos unos 10 metros como mínimo. Para el caso se accede a los edificios por vías que recorren las laderas hasta las cimas. La carencia de planificación de espacios públicos hizo que únicamente las áreas verdes, espacios sobrantes, articularan el espacio de este conjunto. En general se actuó omitiendo las alternativas paisajísticas que ofrecía el cerro en diferentes direcciones y, sobre todo, se distribuyeron los cuerpos indiferentes a las cotas del terreno, como si hubiesen estado emplazados sobre un terreno plano, insensibles a las vistas, al viento, etc.

\footnotetext{
17 “Remodelación en Lota”. AUCA, № 3, abr-may, 1966, p. 19.
} 


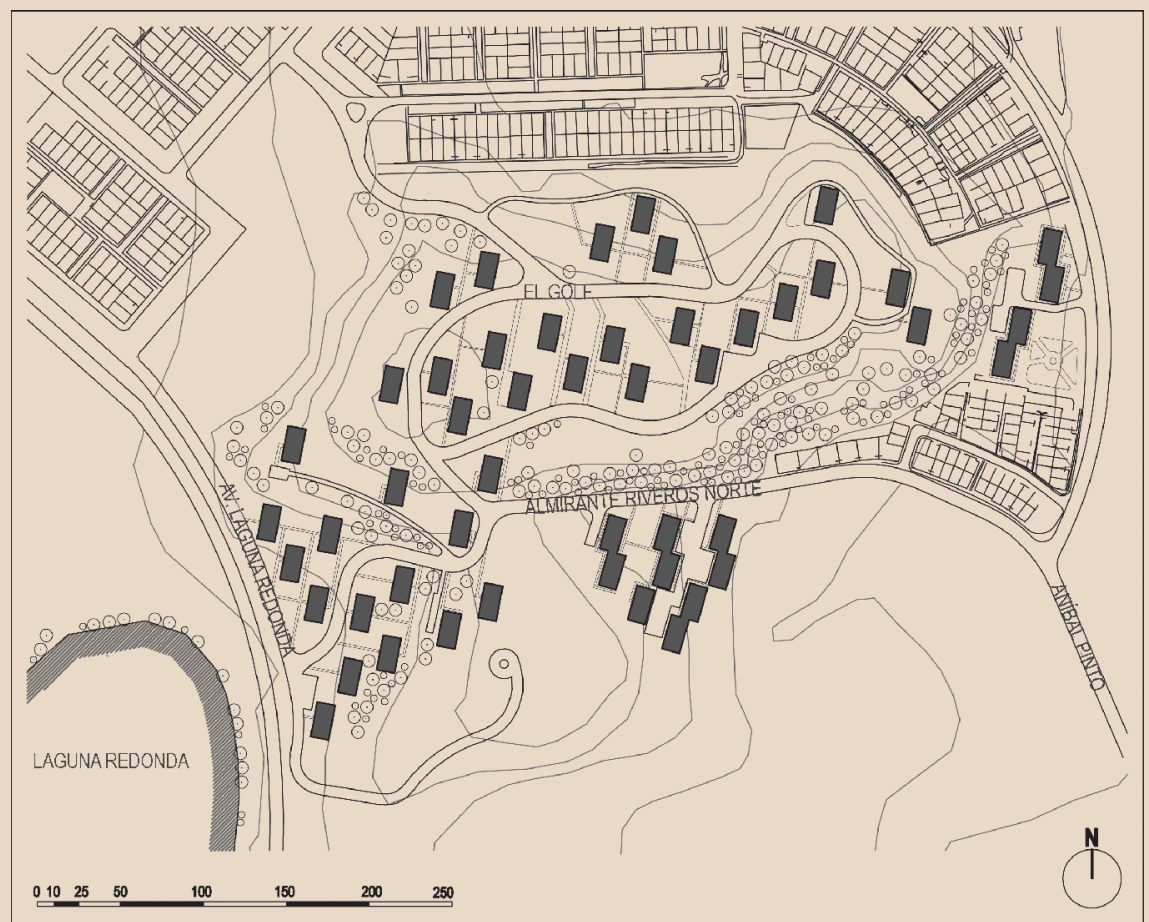

Figura 25. El Golf, Laguna Redonda. (Dibujo Francisca Valencia).

En el mismo sentido, las Viviendas Cooperativa Concepción (Fig. 26), proyecto de mediados de los años sesenta de Jorge Labarca y Boris Áptecar ubicado en el encuentro de la Avda. Pedro de Valdivia y Víctor Lamas, inspira nuevas interpretaciones. Para el caso, el conjunto de 23 viviendas pareadas en tres hileras se emplaza al pie del cerro Caracol. Su agrupación en torno a un patio común instalada en un zócalo elevado sobre la calle, permite la percepción de una meseta que tiende a separarse del plano de la ciudad en busca del aislamiento residencial y de la búsqueda de vistas al río Bío-Bío ${ }^{18}$.

18 “23 viviendas Cooperativa Bío-Bío”, AUCA, 13, dic, 1968, p. 41. 


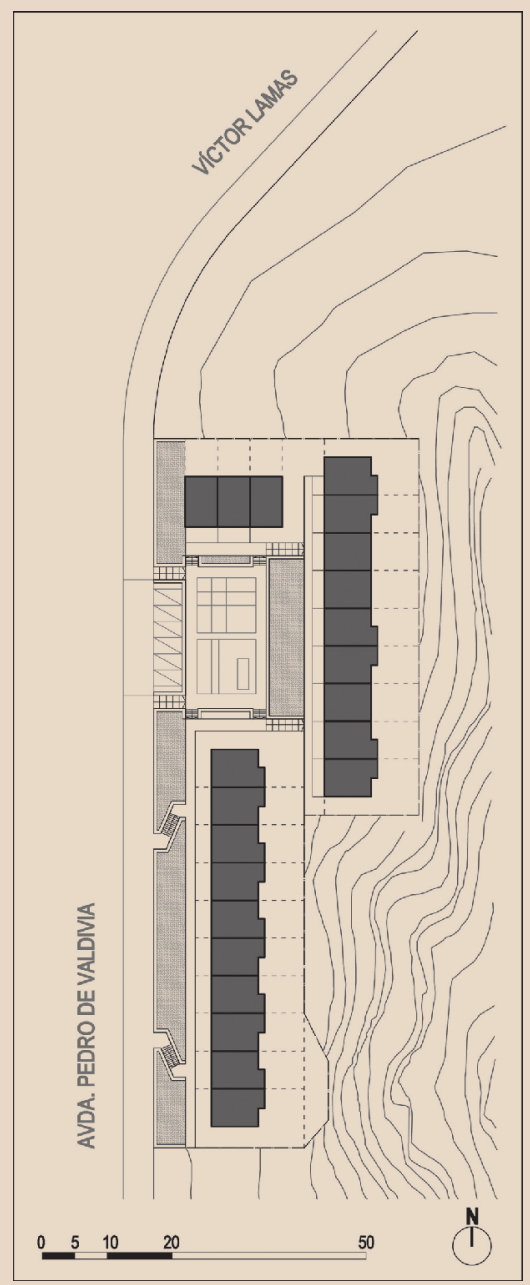

Figura 26. Jorge Labarca. Viviendas Cooperativa Concepción. (Dibujo Francisca Valencia).

Estas intervenciones adelantan una tendencia que en la década de los ochenta dio curso a una nueva modalidad, que defendió políticas afianzadas en la especulación inmobiliaria al servicio de clases medias y altas, a las que se ofreció una nueva manera de ocupar el espacio urbano y también geográfico. Por una parte, el espacio urbano fue abandonado en beneficio de la segregación social y espacial. Por otra, la apropiación privilegiada de grupos poderosos de colinas, vistas y terrenos hasta entonces sin ocupación, terminó por generar un modo gregario de urbanismo. 
La geomorfología es una presencia tan poderosa como la memoria material de la ciudad construida (Parcerisa y Rubert, 1997: 33). Su relevancia en el Área Metropolitana de Concepción admite rasgos geográficos específicos que participan históricamente del desarrollo urbano después del terremoto y maremoto de 1751, a partir de la ocupación de la unidad geográfica del Valle de La Mocha en 1765. Desde entonces ella acoge el crecimiento espacial del núcleo de la conurbación. Así, el desarrollo urbano de esta área se emplaza en las faldas de la cordillera de Nahuelbuta, lo que marca el desarrollo racional en la ocupación sistemática de pequeñas llanuras, micro-valles, etc. A partir de esta circunstancia durante el siglo XX se van integrando instalaciones industriales y conjuntos residenciales de características diversas, agrupados fundamentalmente entorno a los corredores de salida del llano hacia el exterior del núcleo, configurando ejes de crecimiento: Avenida Los Carrera en el núcleo metropolitano y de allí, el eje Concepción - Talcahuano (por Avda. Colón), el eje Concepción - Penco, el eje Concepción - Hualqui y el eje Concepción - Lota. Estas franjas de crecimiento resultan de las características geográficas del territorio y son puestas en relieve por la posición de las infraestructuras viarias, la red de ferrocarriles y algunos ámbitos singulares por su especificidad geográfica, como frentes fluviales, cerros-isla o micro-valles. En resumen, las principales aportaciones de la industria y el Estado para un urbanismo institucional quedaron determinadas por estas circunstancias. Así, hay un correlato entre el soporte geográfico, el emplazamiento industrial, y la localización habitacional organizada.

De este modo, las principales expresiones materiales de este correlato han sido:

Primero, que estas vías estructurantes metropolitanas sirvieron de conexiones entre las principales actividades industriales de la zona y por su intermedio se vitalizaron con la instalación de numerosos conjuntos residenciales de origen institucional en el que destaca en igual grado de importancia el aporte de las propias industrias y el Estado. En consecuencia, conviene afirmar que las vías mencionadas fueron tan importantes para la localización industrial como para la consecuente implantación de la residencia moderna institucional. 
Segundo, que se revela que hay una correlación entre los tamaños de las intervenciones (modificaciones prediales, composiciones volumétricas, etc.) y las capacidades operacionales de los actores y agentes locales. En este sentido, no existen grandes fuerzas productivas que permitan llevar acabo intervenciones o emprendimientos de grandes magnitudes, sino que se establece una relación que determina el espacio público de las diferentes partes de la ciudad remitido a pequeñas plazas, calles, pasajes, etc. Esta homogeneización se extiende a la configuración social de la ciudad en base a un proletariado urbano y a la clase media. Es decir, por lo menos durante el siglo XX, no es una ciudad con un espacio urbano fragmentado notoriamente por clases sociales, cuestión que le aporta un carácter específico a toda el Área Metropolitana.

Tercero, en este sentido se observa que los grandes conjuntos residenciales han sido agentes promotores del espacio público metropolitano, entendido éste en la forma de pasajes, remansos, pequeñas plazas, etc. Asimismo, estos grandes conjuntos han sido estructuras formales muy permeables, con generosos espacios libres y verdes de uso público, contribuyendo decisivamente a la formación de una sociedad urbana específica, fundamentalmente clase media, vinculada a un tipo de soporte económico mediano y a un tipo de espacialidad más asociada a la escala del barrio que a la urbe. Ello también explica que las piezas arquitectónicas tuvieron y se mantuvieron en un nivel de justeza y medida de escala intermedia.

Cuarto, en ese marco, de una u otra manera la idea de manzana persistió, sin promover tipos edificatorios sustancialmente diferentes, siendo fuertemente determinados por la racionalidad y el control de sus dimensiones. Por lo mismo, siempre se prefirió lo peatonal a lo vehicular, la plaza al parque, el pasaje a la avenida.

Finalmente, el correlato entre la gestión institucional, los principios del urbanismo moderno y el control del espacio residencial metropolitano persistió hasta entrados los años setenta, cuando una nueva modalidad espacial alteró la disposición de nuevos conjuntos habitacionales. A la postre nuevos desarrollos residenciales comenzaron a ocupar terrenos hasta entonces omitidos por el desarrollo urbano. De este modo, hacia finales de la década varios asentamientos comenzaron a desplegarse por las laderas y cimas de algunos cerros, ocupando pendientes y mesetas a contracorriente de una práctica hasta entonces dada por racional. Las vistas, la observación del horizonte, el paisaje observado como sobrevuelo, las perspectivas panorámicas se impusieron como un nuevo valor asociado a la ocupación resi- 
dencial. Este valor, coligado a una clase social en ascensión dio paso a nuevas conformaciones que caracterizan el ulterior desarrollo metropolitano, esta vez admitiendo una segregación social que entraba en correspondencia ideológica con un sistema económico absorbido por la oferta y la demanda, más que por el bienestar colectivo. De este modo, las nuevas configuraciones del área metropolitana se reforzaron con conjuntos abiertos y cerrados que ratificaron el aislamiento espacial como paradigma habitacional.

\section{REFERENCIAS}

Aravena, R. (2008). "Historia industria textil Chiguayante". Disponible en Internet: http://raravenahistoria2008.blogspot.com/2008/11/historia-industria -textil-chiguayante.html [Consulta: 12.09.11].

Cáceres, G. (1992). "La voz pública de los arquitectos organizados. Vivienda popular y desarrollo urbano 1934-92", CA. Revista Oficial del Colegio de Arquitectos, № 68, 102-107.

Campos Harriet, F. (1979). Historia de Concepción 1550-1970. Santiago de Chile: Talleres Gráficos de la Universidad Técnica del Estado.

"Concurso población obrera Caupolicán-Chiguayante" (1946, abril). Arquitectura y Construcción, No 5, 75-82.

Corporación de la Vivienda (1961). Villa San Pedro Concepción. Santiago de Chile: Editorial Universitaria S.A.

De la Fuente, H.; Ramírez, H.; Siegmund, S. (1983). Influencia de la Compañía de Acero del Pacífico en el Desarrollo Habitacional de la Conurbación Concepción-Talcahuano. Seminario Inédito, Universidad del Bío-Bío, Concepción.

Franck, S.; Pérez, L. (2009). "Más que una suma de casas: la unidad vecinal Villa San Pedro de Coronel”, Revista INVI, Vol. 24, No 67, 127-152.

Fuentes, P. (2006). "Mort de la rue o la introducción de los principios del urbanismo moderno en Chile. Ejercicios de la época", Revista Urbano, Vol. 9, No 14, 27-33.

Fuentes, P.; Pérez, L. (2007). "Vivienda obrera en Concepción. La Villa Presidente Ríos, primera ciudad moderna en Chile". En Castillo, Ma J. e Hidalgo, R. (Eds.). 1906/2006 Cien años de política pública de vivienda en Chile. Ediciones UNAB, Serie Arquitectura No 1, serie Geolibros No 10, Facultad de Geografía y Diseño UNAB - Instituto de Geografía UC, Santiago de Chile.

M. A. B. (1983, julio 17). "Concepción y sus barrios", El Sur, III.

Navarrete, A.; Hinostroza, G. (2009). "Nuevos enfoques para una historia social de las textiles de Tomé". Cuadernos de Historia Marxista. Vol. I, No 2. Disponible en http://www.rebelion.org/docs/87382.pdf [Consulta: 03.11.11].

Pacheco, A. (1997). Historia de Concepción. Siglo XX. Concepción: Ediciones Universidad de Concepción, Colección Cuadernos del Bío-Bío.

Parcerisa, J. y Rubert, M. (1997). "La condición periférica a Barcelona. Revista Papers. Regió metropolitana de Barcelona, No 26, 29-36. 
“Remodelación Concepción”, AUCA, № 15 (1969, jun.-jul.), 66-68.

"Remodelación en Lota”. AUCA, No 3 (1966, abr.-may.), 19.

"Remodelación San Borja”, AUCA, No 16 (1969, ago.-sep.), s/p.

Risopatrón, A. (1947). "Nuestra Institución Gremial. La Asociación y el Colegio de Arquitectos de Chile”. Arquitectura y Construcción, No 11, pp. 37-40.

Schultz, H. (1983, septiembre 4). "Génesis de una memoria urbana”, diario El Sur (Sección Arquitectura y Urbanismo), III.

Sharp, T. (1947). Urbanismo. Buenos Aires: Ediciones Pingüino/Lautaro.

Ulloa, B.; Uribe, R. (2009). Labor de la CORMU en la intercomuna de Concepción entre los años 1970-73. Seminario inédito, Universidad del Bío-Bío, Concepción.

Vallejos, S. (2009). Conjuntos residenciales Lorenzo Arenas 2 y Laguna Redonda: Arquitectura moderna en Concepción. Seminario inédito, Universidad de Concepción.

“23 viviendas Cooperativa Bío-Bío” (1968, dic.), AUCA, 13, 41. 